\title{
Research Joint Ventures and Optimal R\&D Policy with Asymmetric Information
}

\author{
Bruno Cassiman* \\ Universitat Pompeu Fabra \\ Department of Economics and Business
}

October 1994

Revised: December 1997

\footnotetext{
* Mailing address: Department of Economics and Business, Universitat Pompeu Fabra, Ramon Trias Fargas 25-27, 08005 Barcelona, Spain Tel: 34-3-542 27 23; Fax: 34-3-542 17 46; Email: cassiman@upf.es
} 


\begin{abstract}
When to allow Research Joint Ventures (RJVs) or not is an important instrument in the development of an optimal R\&D policy. The regulator, however, is unlikely to know all the relevant information to regulate $R \& D$ optimally. The extent to which there exist appropriability problems between the firms is one such variable that is private information to the firms in the industry. In a duopoly setting we analyze the characteristics of a second-best $R \& D$ policy where the government can either allow RJVs or not and give lump-sum subsidies to the parties involved. The second-best R\&D policy without subsidies will either block some welfare improving RJVs or allow some welfare reducing ones. With lump-sum subsidies, the second-best policy trades off the expected subsidy cost with allowing welfare decreasing RJVs or blocking welfare increasing ones.
\end{abstract}

Keywords: Research joint ventures; R\&D policy; Asymmetric information; Revelation mechanism

JEL classification: L13, L50, D82, O32 


\section{Introduction}

Two features distinguish R\&D from ordinary capital investments. First, $R \& D$ is a public good (Arrow (1962), Grossman and Shapiro (1986)). The use by one firm of the information produced by its $R \& D$ investments does not diminish the amount of information available to other firms. The optimal economy wide allocation would therefore involve the free distribution of this information. Second, R\&D investment is plagued by an externality problem. Firms investing in R\&D typically can not fully appropriate the results from their own R\&D investments. This tends to reduce the incentive to invest in R\&D when firms act non-cooperatively (Spence (1984), d'Aspremont and Jacquemin (1988), De Bondt and Veugelers (1991), Kamien, Muller and Zang (1992)). ${ }^{1}$ In this paper we concentrate on two policy options that have been proposed to reduce these market failures: internalization of the externality and subsidies (Katz and Ordover (1990)). One way to avoid the appropriability problem is to internalize the spillovers by forming Research Joint Ventures (RJV). In a RJV the firms internalize the positive effect these spillovers have on the R\&D and profits of their partners by deciding jointly on their $R \& D$ investments, taking their spillovers into account. Subsidies provide an additional R\&D policy instrument to improve the allocation of resources to R\&D investments (Brodley (1990), Jacquemin (1988)). Subsidies can be lump-sum transfers which implement the R\&D policy or per unit $R \& D$ subsidies which change the marginal incentive to invest in $R \& D$. In this paper we only consider lump-sum subsidies that implement the R\&D policy. A subsidy per unit of $R \& D$ creates additional incentive problems in reporting the true level of $R \& D$ investments and would complicate the analysis considerably. ${ }^{2}$

\footnotetext{
${ }^{1}$ However, see Levin and Reiss (1988), Cohen and Levinthal (1989) and Papaconstantinou (1990) for a different result.

${ }^{2}$ Brown (1984) noted a significant increase in R\&D expenditures reported on tax forms in response to the tax credit for increases in R\&D spending of the 1981 Economic Recovery Act. The increase greatly exceeded the growth in spending reported in Business Week's survey of R\&D expenditures. This divergence between growth rates is consistent with the existence of an informational problem in reporting the true level of $R \& D$ expenditures.
} 
When firms are allowed to form RJVs, $R \& D$ investments increase with the level of spillovers, exceeding the non-cooperative investment level when the spillovers are substantial (d'Aspremont and Jacquemin (1988), De Bondt and Veugelers (1991)). Firms that cooperate in R\&D might thus not only increase profits but also welfare when the spillovers are substantial. Policywise, a case can then be made for allowing RJVs to form when there are high spillovers in R\&D. However, when there are low or no spillovers, firms acting non-cooperatively with respect to R\&D bring about higher welfare than when allowed to form a RJV. The only effect of a RJV in this case is to reduce R\&D competition, which in turn decreases welfare (Katz (1986)). ${ }^{3}$ This theoretical finding has fueled the debate on the issue of relaxing antitrust regulation with respect to RJVs. Everybody agrees on the benefits due to internalizing the externality by means of a RJV when the information leakage is substantial (Jacquemin and Soete (1994)). However, the debate on the exact implementation of this policy is still ongoing. In evaluating cooperative $R \& D$ regulators often use the same "rule of reason" as in the case of mergers. Given the dynamic nature of $R \& D$, insensitive application of these static merger guidelines may lead to undesirable outcomes (Ordover and Willig (1985)). Appropriate standards for evaluating RJVs should be developed. Jorde and Teece (1990) propose the creation of an administrative procedure for evaluating and possibly certifying cooperative $R \& D$ agreements in order to establish a safe harbor from antitrust litigation. Shapiro and Willig (1990) claim that this would amount to giving RJVs a blank check. They argue that a regulator needs a great deal of information to evaluate a RJV and much of this information might be proprietary. Similarly, Geroski (1992) states that since there is no presumption that the benefits of RJVs will be large or easily realized in every case, the design of the policy is likely to be

\footnotetext{
${ }^{3}$ It has often been suggested that RJVs might also facilitate collusion in the output market. We do not exclude the possibility that firms in a RJV behave more cooperatively in the output market. A necessary condition for a RJV to be welfare improving in this case is that total R\&D investments increase. See Yi (1995) for an analysis of the welfare effects of product market collusion by an industrywide RJV. We abstract from any dynamic considerations in this paper. See Martin (1993) for an analysis of the increased potential for tacit collusion in RJVs. For an analysis of the effects of collusion in the output market on RJV formation, see Greenlee and Cassiman (1996).
} 
critical. In fact, as we will argue in this paper, the spillover level of individual firms may be private information of the firms within the industry and this will influence the design of the optimal R\&D policy.

Both the formation of RJVs and the public funding of R\&D projects have increased in recent years (Jacquemin and Soete (1994)). The most systematic evidence on the formation of RJVs are the registrations of RJVs in the USA under the National Cooperative Research Act (NCRA). By registering under the NCRA, firms become exempt from treble damages under antitrust regulation. However, cooperative $R \& D$ ventures need not register under the NCRA. In that case they are liable under the usual antitrust regulation. Since the passage of the NCRA in 1984 until 1994, 453 new RJVs have filled in the United States. ${ }^{4}$ From these registrations it seems that collaborative research is a more dominant form of an innovation-related strategy among firms within the manufacturing sector (Link (1996)). The issue we are concerned about in this paper is that maybe too many RJVs form unchallenged and that asymmetric information between the regulator and the industry biases the type of RJVs that actually register. Scott (1988) notes that evidence on the effect of the NCRA suggests that cooperative research registered under the NCRA does not happen in industries with severe appropriability problems. According to the theory, RJVs formed by these firms would then most likely decrease welfare. Firms that form RJVs and do not register under the NCRA, consider antitrust charges extremely unlikely because their cooperative agreements do not conflict with regulatory objectives and at the same time they avoid publicizing their cooperative ventures. In Europe the 1986 Single European Act amendments to the Treaty of Rome gave the Community specific responsibility for strengthening "the scientific and technological basis of European industry." In addition

\footnotetext{
${ }^{4} \mathrm{An}$ RJV, as defined in the NCRA, is "any group of activities, including attempting to make, making or performing a contract by two or more persons for the purpose of (A) theoretical analysis, experimentation, or systematic study of phenomena or observable facts, (B) the development or testing of basic engineering techniques, (C) the extension of investigative findings or theory of scientific or technical nature into practical application for experimental and demonstration purposes..., (D) the collection, exchange, and analysis of research information, or (E) any combination of the [above] (Link (1996)).
} 
to the EEC block exemption of Article 85(1) of the EC treaty for cooperative ventures in $R \& D$, a variety of programs were initiated, many of which explicitly fostered interfirm cooperation tied to Community funding for part of the R\&D costs of the proposed projects (Geroski (1992), Martin (1996)). There is less systematic evidence on cooperative ventures in Europe, but the available evidence suggests that the number of RJVs has been rapidly increasing (Hagedoorn and Schakenraad (1992), Jacquemin and Soete (1994), Kleinknecht and Reijnen (1992)). The EC budget for funding cooperative R\&D projects has also been steadily increasing over the years (Peterson (1991)).

In our model the government ${ }^{5}$ has two R\&D policy instruments at its disposal. First the government can allow or prohibit the formation of a RJV. We assume that firms cannot be forced into a RJV against their will, so that RJVs form only when profitable. The regulatory policy analyzed here consists of an evaluation process which allows RJVs to form with a certain probability depending on the reported appropriability problems. The second policy instrument is subsidizing R\&D where subsidies are assumed to be lump-sum transfers. The regulator chooses its policy in order to maximize social welfare taking into account its information disadvantage regarding the true level of $R \& D$ spillovers. This is an implementation problem with asymmetric information between a regulator and an oligopoly. ${ }^{6}$ The resulting policy can be formulated as follows: firms wishing to engage in cooperative research apply to the government for permission. Firms simultaneously and independently report their own spillover level to the government. The probability that a RJV will be approved and the level of lump-sum subsidies are a function of these reports. The first-best policy always allows a RJV when at least one firm has high spillovers. However, given asymmetric information the first-best policy can not be implemented. The second-best R\&D policy is industry specific and depends on the beliefs of the regulator about the spillover

\footnotetext{
${ }^{5}$ We will use government and regulator interchangeably throughout this paper.
} 
situation of the industry. The regulator will either allow some welfare reducing RJVs or block some welfare enhancing RJVs. Firms within industries that are typically characterized by high spillovers will always be allowed to form RJVs. When low spillovers are most likely, no RJVs are allowed to form. In intermediate cases the second-best $R \& D$ policy improves upon this unsophisticated $R \& D$ policy by setting up a policy that screens for the different spillover states of the industry. In order to induce truthful revelation in this case, the second-best policy deviates from the first-best by either allowing RJVs to form with some probability when spillovers are low or restricting the formation of RJVs when spillovers are high. The lump-sum subsidies improve this screening capability of the regulator. The second-best policy developed in this paper differs from the existing R\&D policies in the USA and Europe by conditioning the R\&D policy on industry (or firm) specific information. It is important to screen for undesirable RJVs when the appropriability conditions of the industry are not clear to the regulator. In particular, if we believe that it is easy to exaggerate the existence of spillovers and if information between the regulator and the industry is asymmetric, it seems to be important to scrutinize proposed RJVs more closely. In the USA there is some evidence that the current policy might actually encourage undesirable RJVs to register under the NCRA while in Europe there is little control over the RJVs that do form given the EEC block exemption of Article 85(1) of the EC treaty for cooperative ventures in $R \& D$.

This paper is closely related to the papers by Demski and Sappington (1984) and Cremer and McLean (1988) which study optimal mechanism design by a principal with multiple agents. Both papers find that when the information of the agents is correlated and the agents are risk neutral, the first-best can be implemented. Our approach differs from theirs in two ways. First, we analyze the effect of restricting the policy instruments of the regulator. If no transfers are possible between the regulator

\footnotetext{
${ }^{6}$ Mechanism design in a regulatory context with more than one firm has been a fruitful new direction in the regulation literature (Baron (1989), Anton and Yao (1989), Auriol and Laffont (1992), Demski and Sappington (1984), McGuire and Riordan (1991), Olsen (1993), Wolinsky (1993)).
} 
and the agents, the regulator, by allowing or blocking the formation of a RJV, does not posses enough degrees of freedom to implement the first-best. This is the case because the policy regulates the conduct of both agents at the same time. Second, if transfers are allowed, we assume that they are costly and cannot be negative. Implementing the first-best mechanism of Demski and Sappington (1984) might be extremely costly. In our model the regulator will trade off expected subsidy payments to the agents with implementing the first-best policy. In order to implement the mechanism by Cremer and McLean (1988), the regulator needs to impose large negative transfers on the agents with small probability. This mechanism cannot be implemented because we feel it is reasonable to assume that the regulatory agency responsible for implementing the $R \& D$ policy usually cannot extract large payments from the firms.

Besanko and Spulber (1993) also analyze the effect of asymmetric information between the regulator and the industry on the optimal merger policy, while restricting the policy instruments of the regulator. There are two important distinctions between their model and ours. First, their merger policy is not a revelation mechanism that screens for the private information of the merging firm (its true ex-post marginal cost) and second, the regulator is assumed not to be able to commit to a probability of challenging the merger. In our model the regulator commits to a probability of challenging the RJV and this probability is conditioned on the reports of the firms. In line with our results, Besanko and Spulber (1993) find that due to asymmetric information some welfare increasing mergers will not be consummated. However, given the 2-dimensional state variable in our model, we also find that some welfare reducing RJVs will be allowed depending on the beliefs of the regulator.

In the next section we set up the general model. In section three we solve the model for the case where no subsidies are provided. Next we solve the general model with lump-sum subsidies. Finally, we conclude by concentrating on policy recommendations. In Appendix B we show that the model of d'Aspremont and 
Jacquemin (1988) is consistent with our more general model assumptions. Due to their simple nature, proofs are relegated to Appendix A.

\section{The Model}

Consider a duopoly where each firm invests in R\&D. The model focuses on the externality problem faced by these firms investing in $R \& D$ as represented by spillovers. R\&D investment spillovers can either be High (H) or Low (L). A high spillover for firm i means that firm $\mathrm{i}$ absorbs a great deal of the knowledge of firm $\mathrm{j}$. At the start of the R\&D project firms only know their own spillover and have beliefs about a rival's spillover. The firms are symmetric except possibly for their spillover. The model, thus, allows for the possibility of asymmetric spillovers where one firm has a high spillover while the other has a low spillover. In industries with a dominant firm and a competitive fringe, it is more likely that information flows from the dominant firm to the fringe. The expected correlation between spillovers of these firms is negative. In other industries, with partners of equal strength, spillovers are expected to be positively correlated. In the R\&D stage the firms can either compete in R\&D or form a RJV. Forming a RJV can be thought of as maximizing joint profits in the R\&D stage. No efficiency gains in $R \& D$ are assumed and no new entity is necessarily created by this agreement. ${ }^{7}$

The government's objective is to maximize social welfare using a R\&D policy with two instruments: (1) allowing research joint ventures (RJVs) or not, and, (2) giving lump sum subsidies to the firms. The government has a probability distribution over the states of the world and there are four states of the world: $S=\{(L, L),(L, H)$, $(\mathrm{H}, \mathrm{L}),(\mathrm{H}, \mathrm{H})\}$, i.e. both firms have low spillovers, one firm has a low spillover while the other has a high spillover or both firms have high spillovers.

\footnotetext{
${ }^{7}$ Fusfeld and Haklish (1985) report that 1/3 of cooperative research is conducted at in-house facilities of the cooperating entities. They also quote John Young, president of Hewlett-Packard on the value of cooperative R\&D: "it will enable US electronic companies to discuss and coordinate our research objectives and to gain leverage on our expenditures". Firms thus contract on the amount of R\&D they will perform, which is consistent with our definition of a RJV. See also Audretsch (1989) and Odagiri (1986) for similar examples of cooperative research in Japan.
} 
The timing of the game is as follows: the government commits to its $R \& D$ policy after which the firms simultaneously submit claims about their spillover level. The true state of the world is revealed to the firms after they filed their reports. They subsequently make their R\&D and output decisions with perfect information. ${ }^{8,9}$

Let $\beta_{i}$ be the spillover level of firm $i$. The beliefs of the government and firms are given by:

Government's Beliefs: $\operatorname{Prob}\left(\beta_{1}=\mathrm{L}, \beta_{2}=\mathrm{L}\right)=\mathrm{p}_{\mathrm{LL}}$,

$$
\begin{aligned}
& \operatorname{Prob}\left(\beta_{1}=\mathrm{L}, \beta_{2}=\mathrm{H}\right)=\operatorname{Prob}\left(\beta_{1}=\mathrm{H}, \beta_{2}=\mathrm{L}\right)=\mathrm{p}_{\mathrm{HL}}=\mathrm{p}_{\mathrm{LH}}, \\
& \operatorname{Prob}\left(\beta_{1}=\mathrm{H}, \beta_{2}=\mathrm{H}\right)=\mathrm{p}_{\mathrm{HH}}, \\
& \quad \text { where } \mathrm{p}_{\mathrm{LL}}+2 \mathrm{p}_{\mathrm{LH}}+\mathrm{p}_{\mathrm{HH}}=1 .
\end{aligned}
$$

Firm i's Beliefs: $\operatorname{Prob}\left(\beta_{\mathrm{j}}=\mathrm{L} \mid \beta_{\mathrm{i}}=\mathrm{L}\right)=\mathrm{p}_{\mathrm{LL}} /\left(\mathrm{p}_{\mathrm{LL}}+\mathrm{p}_{\mathrm{LH}}\right)$,

$$
\operatorname{Prob}\left(\beta_{\mathrm{j}}=\mathrm{L} \mid \beta_{\mathrm{i}}=\mathrm{H}\right)=\mathrm{p}_{\mathrm{LH}} /\left(\mathrm{p}_{\mathrm{LH}}+\mathrm{p}_{\mathrm{HH}}\right) .
$$

\footnotetext{
${ }^{8}$ The important assumption is that firms learn the true spillover levels before making their output decisions and before any profits are realized. If the $R \& D$ project takes time to complete, it seems reasonable that firms learn their rivals true spillover type before any major decisions need to be made (R\&D investments), but after any legal uncertainty about the RJV has been resolved.

${ }^{9}$ This of course is only one of the possible games played. If the firms know the state of the world before reporting, the government can obtain truthful revelation by having both firms report the state of the world instead of only their own spillover. If the reports do not coincide, both firms are punished severely. Alternatively the firms could only file one report. Without subsidies the regulator cannot do better than simply allow or block a RJV based on its beliefs. With subsidies some screening is possible when public funds are not too expensive. In the case that the firms do not learn the true state of the world, the most general game would involve the whole communication game where the payoffs to the players also depends on the reports made to the regulator: the regulator screens the firms while the firms signal their types to each other through their reports. The firms will update their beliefs according to the reports of their rival. This will complicate matters substantially because we cannot rely on the revelation principle any more to solve this game. Truthful revelation is not necessarily an equilibrium of this general game since the report of the firms serves as an announcement to both the government and the firm's rival. Truthful revelation to the regulator implies at the same time truthful revelation to your rival/partner which might not be optimal. See Baron and Besanko (1992) for a model where the regulator chooses the organizational design of the suppliers such that they file a single report or independent reports.
} 
It will be useful to define the marginal probabilities and correlation of the types. Let $\theta=p_{L L}+p_{L H}$ be the marginal probability of type L, while $1-\theta=p_{L H}+p_{H H}$ is the marginal probability of type $\mathrm{H}$. The correlation between the types of the firms is:

$$
\rho=\frac{p_{L L} p_{H H}-p_{L H}^{2}}{\left(p_{L L}+p_{L H}\right)\left(p_{L H}+p_{H H}\right)}, \text { where } 0 \leq \theta \leq 1 \text { and }-1 \leq \rho \leq 1 .^{10}
$$

Define the $R \& D$ policy, $\mathrm{f}$, as follows:

$\mathrm{f}: \mathrm{S} \rightarrow[0,1] \times \Re_{+} \times \Re_{+}$such that $f\left(\hat{\beta}_{i}, \hat{\beta}_{j}\right)=\left[r_{\hat{\beta}_{i} \hat{\beta}_{j}}, S_{\hat{\beta}_{i} \hat{\beta}_{j}}, S_{\hat{\beta}_{j} \hat{\beta}_{i}}^{j}\right]$

where $\hat{\beta}_{i}$ and $\hat{\beta}_{j}$ are the reports of firm $\mathrm{i}$ and $\mathrm{j}$ respectively, $r_{\hat{\beta}_{i} \hat{\beta}_{j}}$ is the probability that the government allows a RJV and $S_{\hat{\beta}_{i} \hat{\beta}_{j}}^{i}$ is the subsidy given to firm i conditional on the reports of the firms. ${ }^{11}$

The R\&D decisions of firms involve many important elements next to spillovers such as demand and cost considerations. In reality the asymmetry of information between the regulator and the industry extends to these parameters as well. It is possible to extend the model to include these elements and its development would follow along the same lines as in this model where we restrict attention to an asymmetry about the spillovers. The new element introduced by this model, is that the policy of the regulator, i.e. allowing a RJV or not, regulates the actions of both firms at the same time and as a result the regulator loses some of his freedom in setting his $R \& D$ policy. Adding lump-sum subsidies to the $R \& D$ policy will not influence the firms' $R \& D$ and output decisions. Let $\mathrm{V}^{\mathrm{nc}}\left(\beta_{\mathrm{i}}, \beta_{\mathrm{j}}\right)$ be firm i's profits without subsidies when the firms are not allowed to form a RJV (non-cooperative) in state $\left(\beta_{\mathrm{i}}, \beta_{\mathrm{j}}\right)$, and let $\mathrm{V}^{\mathrm{c}}\left(\beta_{\mathrm{i}}, \beta_{\mathrm{j}}\right)$ be firm i's profits when they are allowed to form a RJV (cooperative). Similarly define $\mathrm{W}^{\mathrm{nc}}\left(\beta_{\mathrm{i}}, \beta_{\mathrm{j}}\right)$ as the social welfare resulting in state $\left(\beta_{\mathrm{i}}, \beta_{\mathrm{j}}\right)$ when the firms

\footnotetext{
${ }^{10}$ Note the following degeneracies: $\quad \rho=-1 \Rightarrow \mathrm{p}_{\mathrm{LH}}=\mathrm{p}_{\mathrm{HL}}=.5, \theta=1 \Rightarrow \mathrm{p}_{\mathrm{LL}}=1, \theta=0 \Rightarrow \mathrm{p}_{\mathrm{HH}}=1$.

${ }^{11}$ We only consider non-negative subsidies for two reasons: first, an institution responsible for R\&D policy usually does not have the authority to tax R\&D and second, when considering a cost of public
} 
are not allowed to form a RJV and $\mathrm{W}^{\mathrm{c}}\left(\beta_{\mathrm{i}}, \beta_{\mathrm{j}}\right)$ the social welfare when firms form a RJV in state $\left(\beta_{\mathrm{i}}, \beta_{\mathrm{j}}\right)$. The following notation will prove useful:

$$
w_{i j}=W^{c}(i, j)-W^{n c}(i, j) \text { and } v_{i j}=V^{c}(i, j)-V^{n c}(i, j) \text {, where } i, j \in\{L, H\} \text {. }
$$

In order to determine the first-best policy that maximizes welfare when the regulator has symmetric information, we need to make some assumptions on the welfare function. ${ }^{12}$ In state $(\mathrm{L}, \mathrm{L})$ welfare is higher when the firms do not form a RJV $\left(\mathrm{w}_{\mathrm{LL}}<0(\mathrm{~A} 1)\right)$. If there are little or no appropriability problems, society is best served by firms competing in $R \& D$. Firms use $R \& D$ strategically to secure market share in the output market. The RJV restricts R\&D compared to the non-cooperative case, leading to higher production costs and lower output which reduces welfare (Katz (1986)).

In the case of severe appropriability problems, total welfare is increased by the formation of a RJV (d'Aspremont and Jacquemin (1988), Katz and Ordover (1990)). When competing in $R \& D$, firms restrict their $R \& D$ expenditures since much of a firm's research output flows to its rival. This externality is internalized by a RJV and as a result society benefits because of increased $R \& D$ investments, lower production costs and consequently a higher output at lower prices $\left(\mathrm{w}_{\mathrm{HH}}>0(\mathrm{~A} 2)\right) .{ }^{13}$

If the spillovers are different we assume that welfare is higher if both firms join in a $\mathrm{RJV}\left(\mathrm{w}_{\mathrm{LH}}=\mathrm{w}_{\mathrm{HL}}>0(\mathrm{~A} 3)\right) .{ }^{14}$ The low spillover firm restricts its $\mathrm{R} \& \mathrm{D}$ investments

funds it might lead to a perverse effect of taxing the firms to make money since the cost of funds now adds to welfare.

${ }^{12}$ In Appendix B it is shown that these assumptions are consistent with existing models of R\&D competition or cooperation with appropriability problems. Note that these assumptions also accommodate the case where the regulator expects that firms that form a RJV collude in the output market.

${ }^{13}$ Note that because of the duopoly setup the RJV solves both the public good problem and the externality caused by the spillover. If there are more than two firms in the industry, the regulator could also use the maximal number of firms allowed into the RJV as a policy instrument. Tentative results seem to suggest that under full information the regulator prefers no RJV in the case of low spillovers and an industrywide RJV in the case of high spillovers. The firms, however, will always prefer some intermediate size of the RJV (Greenlee and Cassiman (1996), De Bondt and Wu (1997), PoyagoTheotoky (1995)).

${ }^{14}$ When firms collude in the output market, this assumption is more likely to be violated. However, with the reverse inequality qualitatively similar conclusions result. 
significantly more compared to the state where its rival also has a low spillover. Forming a RJV restores the incentives of the low spillover firm to invest in R\&D. The increased knowledge flows freely to the high spillover firm. In response the high spillover firm reduces its own R\&D investments only slightly. Whenever the increase in $R \& D$ investment of the low spillover firm outweighs the reduction of $R \& D$ by the high spillover firm and total $R \& D$ investment increases, welfare is improved by the formation of a RJV. The high spillover firm can maintain a competitive advantage in the output market by not reducing its $R \& D$ investment by the same amount as the low spillover firm increases its R\&D in a RJV and thus capturing a larger market share in the output market.

The firms always prefer to form a RJV ( $\mathrm{v}_{\mathrm{ij}}>0 \forall \mathrm{i}, \mathrm{j} \in\{\mathrm{L}, \mathrm{H}\}$ (A4)). A RJV can coordinate the $R \& D$ investments of both firms such that total joint profits are maximized. If we assume that transfers are allowed in the case of a RJV, the firms prefer the RJV to competition in R\&D. ${ }^{15,16}$

Given these assumptions, the first-best policy is to allow RJVs if at least one of the firms has a high spillover. If both firms have a low spillover they will be required to compete in $R \& D$. If there is a cost of public funds, $\lambda$, the regulator will not use any subsidies since they are merely a costly transfer of funds. Every dollar spent by the government, costs society $1+\lambda$ dollars.

When the spillover level of a firm is private information, the first-best policy is not feasible. A conflict arises between the government's objective and a firm's objective in the state $(\mathrm{L}, \mathrm{L})$. A low spillover firm has an incentive to claim that its spillover is

\footnotetext{
${ }^{15}$ We will not consider potential incentive problems between the partners of a RJV (see Veugelers and Kesteloot (1994), and, Perez-Castrillo and Sandonis (1997)).

${ }^{16}$ Note that the model does not specify the split of rents that result from the formation of the RJV between the firms. If the division of rents is a function of the announced spillovers, this would create additional strategic incentives in the announcement game (see also footnote 9). In the model we assume that all uncertainty about the spillovers is resolved before investment and production. In that case the true spillovers are know at the time the rents are realized and there is no opportunity for strategic interaction between the firms with respect to the spillover announcement in order to capture a larger share of the rents.
} 
high. By doing so, the firm can guarantee approval of a RJV, which it prefers by (A4). To solve this problem the government must adjust its $R \& D$ policy to reflect firms' incentives to misreport their private information. By the revelation principle the government can restrict attention to mechanisms that require the firms to report truthfully and give no incentive to cheat (Baron and Myerson (1982), Baron (1989)).

The government has to solve the following program:

$$
\operatorname{MAX}_{\left\{r_{i j}, S_{i j} \forall i, j \in\{L, H\}\right\}} E W=W_{o}+\sum_{i, j=L, H} p_{i j}\left(r_{i j} w_{i j}-2 \lambda S_{i j}\right)
$$

subject to:

$$
\begin{array}{r}
I C(i) \quad \sum_{j=L, H} p_{i j}\left[v_{i j}\left(r_{i j}-r_{k j}\right)+S_{i j}-S_{k j}\right] \geq 0, \quad \forall i, k \in\{L, H\}, i \neq k . \\
0 \leq r_{i j} \leq 1, r_{i j}=r_{j i}, S_{i j} \geq 0, \quad \forall i, j \in\{L, H\} .
\end{array}
$$

where EW is the expected welfare of society, $\lambda$ is the cost of public funds, and $\mathrm{W}_{\mathrm{o}}=\mathrm{p}_{\mathrm{LL}} \mathrm{W}^{\mathrm{nc}}(\mathrm{L}, \mathrm{L})+2 \mathrm{p}_{\mathrm{LH}} \mathrm{W}^{\mathrm{nc}}(\mathrm{L}, \mathrm{H})+\mathrm{p}_{\mathrm{HH}} \mathrm{W}^{\mathrm{nc}}(\mathrm{H}, \mathrm{H})$.

IC(L) is the incentive constraint corresponding to truthful revelation by the low spillover type, while $\mathrm{IC}(\mathrm{H})$ is the incentive constraint for the high spillover type. Since the subsidies are restricted to be non-negative the Individual Rationality constraints are trivially satisfied if the profit levels in the cooperative and the non-cooperative case are non-negative. The probabilities of being allowed to form a RJV are restricted to lie between zero and one.

Next we consider two cases. In the first case the regulator cannot give any subsidies. The only policy instrument is the probability with which to allow RJVs. In the second case the regulator can use lump-sum subsidies together with allowing RJVs or not as a means of $R \& D$ policy.

\section{R\&D Policy without Subsidies}


In the no-subsidy case the only policy tool in the hands of the government is the probability with which to allow a RJV. This simplifies the problem that the government has to solve considerably. Suppose that an unsophisticated government ignores the private information of the firms and only allows or prohibits the RJV based on its own beliefs. This leads to the following policy: the regulator allows RJVs when the marginal probability of the low spillover type, $\theta$, is low. Most likely RJVs are welfare improving in this region. As the marginal probability of the low spillover type increases, there is a point $\left(\mathrm{U}\left(\mathrm{p}_{\mathrm{LL}}, \mathrm{p}_{\mathrm{HH}}\right)=0\right){ }^{17}$ at which the $\mathrm{R} \& \mathrm{D}$ policy changes to not allowing any RJVs.

The government can improve upon this policy by using firm-reports about their spillovers. However, the Incentive Constraints come in to play. The following propositions summarize the second-best $\mathrm{R} \& \mathrm{D}$ policy. The intuition of the optimal second-best mechanism can be best understood by considering the different regions in $(\rho, \theta)$-space depicted in Figure 1. The full statement of Proposition 1 and 2 and its proof can be found in Appendix A.

Let $\mathrm{f}^{\mathrm{SB}}=\left[\mathrm{r}_{\mathrm{LL}}, \mathrm{r}_{\mathrm{LH}}, \mathrm{r}_{\mathrm{HH}}\right]$ define the optimal second-best R\&D policy and let $\mathrm{U}\left(\mathrm{p}_{\mathrm{LL}}, \mathrm{p}_{\mathrm{HH}}\right)=\mathrm{p}_{\mathrm{LL}} \mathrm{w}_{\mathrm{LL}}+2 \mathrm{p}_{\mathrm{LH}} \mathrm{w}_{\mathrm{LH}}+\mathrm{p}_{\mathrm{HH}} \mathrm{W}_{\mathrm{HH}}$. The second-best R\&D policy can either be a screening policy which separates the states of the world or a pooling policy.

\footnotetext{
${ }^{17}$ Let $\mathrm{U}\left(\mathrm{p}_{\mathrm{LL}}, \mathrm{p}_{\mathrm{HH}}\right)=\mathrm{p}_{\mathrm{LL}} \mathrm{w}_{\mathrm{LL}}+2 \mathrm{p}_{\mathrm{LH}} \mathrm{w}_{\mathrm{LH}}+\mathrm{p}_{\mathrm{HH}} \mathrm{w}_{\mathrm{HH}}$. If $\mathrm{U}\left(\mathrm{p}_{\mathrm{LL}}, \mathrm{p}_{\mathrm{HH}}\right) \geq 0$, the government will always allow RJVs, while if $\mathrm{U}\left(\mathrm{p}_{\mathrm{LL}}, \mathrm{p}_{\mathrm{HH}}\right)<0$, no RJV will be allowed.
} 


\section{Proposition 1:}

The regulator selects a pooling policy,

1. if the state $(L, L)$ is very unlikely $\left(\mathrm{R}_{(1)}\right)$. RJVs are always allowed: $f^{\mathrm{SB}}=[1,1,1]$,

2. if the state $(L, L)$ is very likely $\left(R_{(2)}\right)$. No RJVs are allowed: $f^{S B}=[0,0,0]$,

3. if the high spillover firm is tempted to lie about its true type under the mechanism that induces truthful revelation by a low spillover type. RJVs are always allowed or never allowed, depending on the regulator's beliefs $\left(\mathrm{IH}_{(\mathrm{i})}\right)$ :

$$
\begin{aligned}
& f^{\mathrm{SB}}=[0,0,0] \text { if } \mathrm{U}\left(\mathrm{p}_{\mathrm{LL}}, \mathrm{p}_{\mathrm{HH}}\right) \leq 0, \\
& \mathrm{f}^{\mathrm{SB}}=[1,1,1] \text { if } \mathrm{U}\left(\mathrm{p}_{\mathrm{LL}}, \mathrm{p}_{\mathrm{HH}}\right) \geq 0 .
\end{aligned}
$$

The regulator chooses a separating R\&D policy whenever it is welfare increasing to screen for the state $(\mathrm{L}, \mathrm{L})$ through manipulating the probabilities of allowing a RJV in different states.

Proposition 2:

Let $q=\frac{p_{L H} v_{L H}}{p_{L L} v_{L L}}$. The regulator selects a screening policy,

1. if the states $(\mathrm{L}, \mathrm{L})$ and $(\mathrm{H}, \mathrm{H})$ are more likely $\left(\mathrm{R}_{(3)}\right)$ : $\mathrm{f}^{\mathrm{SB}}=[\mathrm{q}, 0,1]$ if $\mathrm{q} \leq 1$.

2. if the state $(L, H)$ or $(H, L)$ is very likely $\left(R_{(4)}-R_{(5)}\right)$ :

$$
\begin{array}{ll}
\mathrm{f}^{\mathrm{SB}}=\left[0,1, \frac{q-1}{q}\right] & \text { if } \mathrm{q} \geq 1, \\
\mathrm{f}^{\mathrm{SB}}=[1-\mathrm{q}, 1,0] & \text { if } \mathrm{q} \leq 1 .
\end{array}
$$

The second-best mechanism depends critically on the beliefs of the regulator and the firms. The probability of allowing a RJV changes as the underlying beliefs of the government and the firms change. ${ }^{18}$ The following comparative statics results w.r.t. $\rho$ and $\theta$ will help to clarify the intuition of the second-best R\&D policy:

\footnotetext{
${ }^{18}$ Note that the regulator is only indifferent between a screening or a pooling R\&D policy on the border between the regions where the optimal policy switches from a pooling policy to a screening policy.
} 
Proposition 3:

Let $\mathrm{q} \equiv \mathrm{q}(\rho, \theta)$, then $\frac{\partial q}{\partial \rho} \leq 0$ and $\frac{\partial q}{\partial \theta} \leq 0$.

proof: See Appendix A.

In Figure 1 we report the second-best R\&D policy for every region as $\left[r_{L L}, r_{L H}\right.$, $r_{H H}$. This second-best R\&D policy reflects the fact that the regulator foremost has to worry about a low spillover firm lying about its true type. Since the firms and the regulator only have conflicting objectives when the true state of the industry is $(\mathrm{L}, \mathrm{L})$, the second-best policy screens out the state $(\mathrm{L}, \mathrm{L})$ whenever it is welfare increasing to do so. In order for the regulator to accomplish this separation, the probability that a low spillover firm is allowed to form a RJV must be high enough to induce truthful revelation by this low spillover firm. The regulator manipulates this probability through deviations of the R\&D policy from the first best by either allowing RJVs with some probability in state $(L, L)$ or restricting the formation of RJVs in the states $(L, H),(H$, L) or $(\mathrm{H}, \mathrm{H})$. To derive the second-best $\mathrm{R} \& \mathrm{D}$ policy the regulator compares the cost of screening for state $(\mathrm{L}, \mathrm{L})$, measured as the deviation from the first-best, with the cost of a R\&D policy that either never allows RJVs or always allows RJVs.

\section{[Figure 1]}

In regions $\mathbf{R}_{(1)}$ and $\mathbf{R}_{(2)}$ the regulator selects a pooling policy. In region $\mathbf{R}_{(1)}$ the combined probability of states $(\mathrm{H}, \mathrm{H}),(\mathrm{L}, \mathrm{H})$ and $(\mathrm{H}, \mathrm{L})$ is high $(1-\theta$ high). In this case it will be too costly in welfare terms to screen out state $(\mathrm{L}, \mathrm{L})$ and the optimal $\mathrm{R} \& \mathrm{D}$ policy always allows RJVs. As the correlation between the types increases, less weight is put on the asymmetric states $(\mathrm{L}, \mathrm{H})$ and $(\mathrm{H}, \mathrm{L})$ compared to the state $(\mathrm{L}, \mathrm{L})$. The boundary with region $\mathrm{R}_{(3)}$ indicates the point at which it becomes welfare increasing to screen out state $(\mathrm{L}, \mathrm{L})$ at the expense of the welfare in states $(\mathrm{L}, \mathrm{H})$ and $(\mathrm{H}, \mathrm{L})$. In 
region $R_{(2)}$ no RJVs are allowed. If $\theta$ is high, the state $(L, L)$ will be very likely while the occurrence of $(\mathrm{H}, \mathrm{H}),(\mathrm{L}, \mathrm{H})$ or $(\mathrm{H}, \mathrm{L})$ is negligible.

In region $\mathrm{R}_{(3)}$ there exists positive correlation between the types and most probability weight lies on states $(\mathrm{L}, \mathrm{L})$ and $(\mathrm{H}, \mathrm{H})$. The high types will be allowed to form a RJV while the low types will only get to form a RJV with probability q. The firms are punished if the reports are $(\mathrm{L}, \mathrm{H})$ or $(\mathrm{H}, \mathrm{L})$ where the punishment consists of not allowing them to form a RJV. ${ }^{19}$ A low spillover firm refrains from lying because the probability that its rival is also a low spillover firm is high. As the correlation between the types increases, the second-best policy converges to the first-best since the probability of forming a RJV in the state $(\mathrm{L}, \mathrm{L})$, sufficient to induce truthful revelation, goes to zero. Under perfect correlation, given that its rival reveals truthfully, a low spillover firm is indifferent between telling the truth or not. Whatever its report, the firms are not allowed to form a RJV.

The last two regions, $R_{(4)}$ and $R_{(5)}$, involve negative correlation between the types. The probability $\mathrm{p}_{\mathrm{LH}}$, that the firms have different spillovers, is considered very high in both of these cases. A RJV is thus allowed if the firms announce $(\mathrm{L}, \mathrm{H})$ or $(\mathrm{H}$, $\mathrm{L})$. In region $\mathrm{R}_{(5)}$ the regulator has to worry about the low-spillover firm lying, while the probability of $(\mathrm{H}, \mathrm{H})$ is still relatively high. If the low spillover firm lies, the likely report is $(\mathrm{H}, \mathrm{H})$. The probability with which the firms are allowed to form a RJV in this case decreases with a higher marginal probability of the low type which deters the low spillover firm from lying given that the probability of the true state $(\mathrm{L}, \mathrm{L})$ increases. On the boundary of region $\mathrm{R}_{(5)}$ and $\mathrm{R}_{(4)}$ the threat of a low firm lying has become so large (as $\theta$ increases) that the regulator must allow a positive probability of forming a RJV when the state is $(\mathrm{L}, \mathrm{L})$ to keep a low spillover firm truthful. The probability $1-\mathrm{q}$ of allowing a RJV in state $(\mathrm{L}, \mathrm{L})$ increases from zero on the boundary with $\mathrm{R}_{(5)}$ up to the

\footnotetext{
${ }^{19}$ Not allowing a RJV when reporting $(\mathrm{L}, \mathrm{H})$ or $(\mathrm{H}, \mathrm{L})$ is the harshest punishment the regulator can give since we do not allow any transfers between the government and the firms. Even in the case of subsidies, we purposely restrict them to be non-negative.
} 
point where the state $(\mathrm{L}, \mathrm{L})$ becomes too likely. At that point the second-best $\mathrm{R} \& \mathrm{D}$ policy reverts to never allowing RJVs, and we are back in region $R_{(2)}$.

In region $\mathrm{IH}_{(3)}$ in Figure $1,{ }^{20}$ the $\mathrm{IC}(\mathrm{H})$ constraint is binding. In region $\mathrm{IH}_{(3)}$ the probability q of region $\mathrm{R}_{(3)}$ for an $(\mathrm{L}, \mathrm{L})$ report becomes too high, and the high spillover type will lie if he puts high probability on the true state being $(\mathrm{H}, \mathrm{L})$, i.e. if $\rho$ is small. If the high spillover firm lies, the most likely report is $(\mathrm{L}, \mathrm{L})$, which results in the formation of a RJV with a high probability q. Truthfully revealing its type would lead to competition in R\&D. Using Lemma 3 (see Appendix A), we know that the second-best policy in region $\mathrm{IH}_{(3)}$ either allows RJVs in all states or never allows RJVs. ${ }^{21}$

The fact that in our model the regulator has only limited instruments generates interesting results although the information of the agents is correlated. Demski and Sappington (1984) find that when two risk-neutral agents posses private information which is informative about the other agent's information, the principal can withhold all rents from the agents and achieve the first-best solution. In our model, the firms still retain some rents because of their private information. The key distinction is that in our model the regulator has less degrees of freedom in setting its R\&D policy. The firms form the RJV together which implies that $r_{L H}=r_{H L}$. This eliminates the optimal mechanism in dominant strategies that Demski and Sappington (1984) propose. The only way to implement truthtelling as a weakly dominant strategy in this case is by setting $r_{L L}=r_{L H}=r_{H H}$. Unfortunately this implies that there may be other nontruthtelling equilibria of the game.

The second-best R\&D policy reveals two important elements for the actual implementation of an R\&D policy. First, the optimal R\&D policy should depend on the beliefs of the regulator about the appropriability conditions in the industry. This indicates that an optimal R\&D policy is industry specific and a function of parameters that relate to the appropriability conditions of the industry. In high technology sectors

\footnotetext{
${ }^{20}$ similarly for regions $\mathrm{IH}_{(4)}$ and $\mathrm{IH}_{(5)}$ see Appendix A.

${ }^{21}$ In figure 1 we assume: $\mathrm{v}_{\mathrm{LH}} \mathrm{v}_{\mathrm{HL}} \geq \mathrm{v}_{\mathrm{LL}} \mathrm{v}_{\mathrm{HH}}$, in region $\mathrm{IH}_{(3)}$, (A5) holds and $\hat{\alpha} \hat{\gamma} \leq 1$ (see Appendix $\mathrm{A}$ ).
} 
spillovers are more likely to be high relative to more traditional sectors. So we should expect regulators to be more lenient with respect to RJVs in high technology than in more traditional sectors. Second, if the optimal R\&D policy screens for the state $(\mathrm{L}, \mathrm{L})$, the regulator should solicit information about the RJV and the individual firms, in particular about the involuntary spillover that these firms expect to realize, whether they compete in R\&D or form a RJV. Firms that announce having high spillovers should argue their case, f.i. through referring to their organizational learning capabilities in other R\&D projects or to other mechanisms that allow them to absorb information more readily. Through its R\&D policy the regulator needs to commit to allow some of the RJVs when they are not efficient in order to minimize information manipulation by the firms. The case of self-selection of low spillover firms that have registered under the NCRA illustrates this potential for information manipulation by the firms and the industry and should put regulators on alert with respect to uncritically approving RJVs. This, however, points to one potential problem with the implementation of the proposed mechanism in the case of a screening policy: the government needs to be able to credibly commit to the mechanism. Ex post renegotiation needs to be avoided. In addition, the firms applying to form a RJV have an incentive to try to manipulate the decision of the regulator through lobbying or bribes. These problems are not specific to this regulatory situation and policy makers have dealt with these issues through clear guidelines and monitoring. ${ }^{22}$

An alternative application of the model is a situation where two suppliers of a firm or two government contractors want to form an alliance to design components and deal with their common customer as a single decision maker. Jointly designing components might generate efficiencies for both suppliers. Part of these benefits will flow to the customer, but the customer worries about the final price that the suppliers will charge for the components. In the case that the final price cannot be specified ex ante, the customer might lose some of its ex-post bargaining power vis-à-vis its

\footnotetext{
${ }^{22}$ See Besanko and Spulber (1993) where the merger guidelines are optimally adjusted to take into
} 
suppliers by allowing them to form an alliance. Clearly, if the alliance provides no cost efficiencies, the customer prefers to enjoy its bargaining power and deal with the suppliers separately. The mechanism developed in this paper, where suppliers announce to the customer the expected efficiencies generated by an alliance and the customer decides whether to approve of this alliance or not, would be the second-best contract given the information asymmetry between the customer and its suppliers. One key element of the model is that the efficiencies realized by the suppliers are not necessarily equivalent and the customer has to trade off efficiencies of the suppliers with the loss of bargaining power due to dealing with a single decision maker in the future.

\section{R\&D Policy with Lump-Sum Subsidies}

We now turn to the case where in addition to allowing RJVs or not, the regulator can also provide a lump-sum subsidy. The government has to solve the general program defined in section 2 . The intuition for the subsidy case closely follows that of the no-subsidy case. The ability to subsidize the firms increases the policy options of the government. It follows that welfare cannot decrease. At worse, if public funds are extremely costly, no subsidies will be used as a R\&D policy tool and the government will either allow RJVs or not as described in Proposition 1 and 2. This result is formulated in Proposition 4.

Proposition 4: Let $\lambda^{*}=\frac{-w_{L L}}{2 v_{L L}} \geq 0$. If $\lambda \geq \lambda^{*}$, then the second best R\&D policy, $\mathrm{f}^{\mathrm{SB}}$, coincides with the no-subsidy case.

Proof: See Appendix A.

The critical level of cost of funds $\lambda^{*}$ is determined by the ratio of the gain in total welfare of not allowing a RJV in the state $(\mathrm{L}, \mathrm{L})$ to the gain in total producer surplus by the formation of a RJV in the state (L, L). If public funds are not very costly, then subsidies can be used as an extra means of screening for the state $(\mathrm{L}, \mathrm{L})$. The first- 
best $R \& D$ policy $f^{\mathrm{FB}}=[0,1,1]$ can be implemented with an expected subsidy of $\mathrm{p}_{\mathrm{LL}} \mathrm{V}_{\mathrm{LL}}$ to the low spillover firm. ${ }^{23}$ However, as the following proposition states, the secondbest $R \& D$ policy trades off expected subsidy payments with implementing the first-best R\&D policy.

\section{Proposition 5:}

Let $q=\frac{p_{L H} v_{L H}}{p_{L L} v_{L L}}$ and $\mathrm{S}=\mathrm{p}_{\mathrm{LL}} \mathrm{S}_{\mathrm{LL}}+\mathrm{p}_{\mathrm{LH}} \mathrm{S}_{\mathrm{LH}}$. The second-best R\&D policy with subsidies is characterized as follows:

1. If the state $(\mathrm{L}, \mathrm{L})$ is not very likely $\left(\mathrm{R} \lambda_{(1)}\right)$ : the first-best $\mathrm{R} \& \mathrm{D}$ policy

$$
\mathrm{f}^{\mathrm{FB}}=[0,1,1] \text { is implemented with } \mathrm{S}=\mathrm{p}_{\mathrm{LL}} \mathrm{V}_{\mathrm{LL}},
$$

2. If the state $(\mathrm{L}, \mathrm{L})$ is very likely $\left(\mathrm{R} \lambda_{(2)}\right): \mathrm{f}^{\mathrm{SB}}=[0,0,0]$ and $\mathrm{S}=0$,

3. If the state $(\mathrm{L}, \mathrm{L})$ and $(\mathrm{H}, \mathrm{H})$ are more likely $\left(\mathrm{R} \lambda_{(3)}\right)$ :

$$
\mathrm{f}^{\mathrm{SB}}=[0,0,1] \text { and } \mathrm{S}=\mathrm{p}_{\mathrm{LH}} \mathrm{V}_{\mathrm{LH}},
$$

4. If the state $(\mathrm{L}, \mathrm{H})$ or $(\mathrm{H}, \mathrm{L})$ is very likely $\left(\mathrm{R} \lambda_{(4)}\right.$ or $\left.\mathrm{R} \lambda_{(5)}\right)$ :

$$
\begin{aligned}
& \mathrm{f}^{\mathrm{SB}}=[0,1,0] \text { and } \mathrm{S}=\mathrm{p}_{\mathrm{LL}} \mathrm{V}_{\mathrm{LL}}-\mathrm{p}_{\mathrm{LH}} \mathrm{V}_{\mathrm{LH}}, \quad \text { if } \mathrm{q} \leq 1, \\
& \mathrm{f}^{\mathrm{SB}}=\left[0,1, \frac{q-1}{q}\right] \text { and } \mathrm{S}=0, \quad \text { if } \mathrm{q} \geq 1 .
\end{aligned}
$$

Proof: see Appendix A.

Figure 2 shows the relevant regions. To clarify the relation with the no-subsidy case, the original regions of the no-subsidy case are depicted in dotted lines. As public funds become more costly, the second-best R\&D policy with subsidies converges to the no-subsidy case.

[Figure 2]

\footnotetext{
${ }^{23}$ We need to check that the incentive compatibility constraint of the High spillover type is not violated. See Appendix A for conditions for which this is the case.
} 
In region $\mathrm{R} \lambda_{(1)}$ the first-best policy is implemented. However, because public funds are costly, the first-best welfare level is not attained. The expected subsidy to a firm with a low spillover is equal to the gain in profit from forming a RJV in the state $(\mathrm{L}, \mathrm{L})$. Note also that the region of beliefs, $\mathrm{R} \lambda_{(1)}$, in which this mechanism is sustained, contains the region for which the government always allowed RJVs in the no-subsidy case, i.e. region $R_{(1)}$. Given that the $R \& D$ policy consists of both a probability of allowing the RJV and lump-sum subsidies, the regulator can implement the first-best through a dominant strategy for one of the firms as in Demski and Sappington (1984) if $\mathrm{v}_{\mathrm{LL}}<\mathrm{v}_{\mathrm{HL}}$. In Demski and Sappington (1984) this assumption is satisfied by an assumption on the marginal productivity of the agent. However this assumption need not be satisfied here. In addition there is no cost of funds associated with the transfer of funds to the agent in their model. Implementing the first-best in dominant strategies in our model might be very costly in welfare terms depending on the cost of funds which implies that the second-best mechanism differs from the first-best one. ${ }^{24}$ Cremer and McLean (1988) construct a mechanism in Bayesian strategies which achieves the firstbest whenever there is some correlation between the types of the agents. This mechanism can only be implemented through negative transfers from the regulator to the firms. As correlation between the types goes to zero, these payments by the agents go to infinity, creating a discontinuity at zero correlation (Laffont and Martimort (1997)). We avoid this mechanism by restricting attention to non-negative transfers. As argued before, this seems more reasonable in the case of R\&D policy (footnote 11).

The region for which no RJVs are allowed in any state, region $\mathrm{R} \lambda_{(2)}$, is a subset of that region, $\mathrm{R}_{(2)}$, in the no-subsidy case. In the no-subsidy case it was inefficient not to allow RJVs if the true states where $(\mathrm{L}, \mathrm{H}),(\mathrm{H}, \mathrm{L})$ and $(\mathrm{H}, \mathrm{H})$ in this region. Subsidies increase the power of the R\&D policy. The trade off between subsidies and a more efficient $R \& D$ organization is positive for a subset of $R_{(2)}$ in the no-subsidy case.

${ }^{24}$ If $\lambda=0$, the first-best is always implemented as $\mathrm{R} \lambda_{(1)}$ is the only non-empty region. 
In region $\mathrm{R} \lambda_{(3)}$ the regulator reduces the expected subsidies (rents) to the low spillover types compared to the expected subsidies in region $R \lambda_{(1)}$. Allowing a RJV only in state $(\mathrm{H}, \mathrm{H})$ and not in the asymmetric states accomplishes this. The asymmetric states, $(\mathrm{L}, \mathrm{H})$ or $(\mathrm{H}, \mathrm{L})$ are so unlikely that this trade off is profitable in expected welfare terms. The subsidies will be set at the maximum in the state $(\mathrm{L}, \mathrm{H})$ or $(\mathrm{H}, \mathrm{L})$ (see proof Lemma 4). This keeps the low types honest because of the expected reward. Note that as the correlation of types increases the subsidy converges to zero and the second-best R\&D policy converges to the first-best.

In regions $\mathrm{R} \lambda_{(4)}$ and $\mathrm{R} \lambda_{(5)}$, the asymmetric states are extremely likely. A RJV will always be allowed if the firms report $(\mathrm{L}, \mathrm{H})$ or $(\mathrm{H}, \mathrm{L})$. If $\theta$ is low, the regulator would like to tax the firms in order to implement the first-best policy. Given that this is not an option for the regulator, the second-best $R \& D$ policy reduces the probability of approving a RJV when the firms announce $(\mathrm{H}, \mathrm{H})$. However if the marginal probability of being low $(\theta)$ becomes too high, the regulator will revert to subsidies to keep the low spillover firms truthful. This transition is continuous. As in the no-subsidy case, $\mathrm{q}$ decreases to 1 at the boundary with $\mathrm{R} \lambda_{(4)}$ after which subsidies take over the role of $\mathrm{q}$ in the no-subsidy case. Subsidies are now a more cost efficient means to create separation in region $R \lambda_{(4)}$.

The second-best R\&D policy with lump-sum subsidies reveals that in addition to the policy being industry specific and the need for soliciting private information about the appropriability conditions of the industry, the regulator should be prepared to subsidize low spillover firms if public funds are not too costly. Instead of being too lenient towards the formation of RJVs, the regulator should reward low spillover firms for providing accurate information about the state of the industry which allows the regulator to better judge the welfare effects of the proposed RJVs. In a more general framework these lump-sum subsidies could be part of a R\&D subsidy policy that would also improve the incentives of a low spillover firm to invest in R\&D. By this mechanism the low spillover firms are then rewarded for the provision of a public good. 


\section{Conclusions}

Knowledge resulting from $R \& D$ investments is characterized by both an externality and a public good problem. By implementing a R\&D policy that encourages cooperative $R \& D$ in industries with severe appropriability problems, the government increases social welfare. However, the extent to which appropriability problems exist in a specific industry, is usually private information. Hence, the government should set up its R\&D policy taking this information problem into account.

The government and the firms have conflicting objectives whenever both firms have low spillovers. The optimal R\&D policy screens for the state $(\mathrm{L}, \mathrm{L})$ except when either the state $(\mathrm{L}, \mathrm{L})$ or the state $(\mathrm{H}, \mathrm{H})$ is extremely likely, or, when high and low spillover firms can not simultaneously be induced to reveal their type truthfully. In the no-subsidy case the probability of allowing a RJV is such that a low spillover firm has no incentive to lie about its spillover in order to be allowed to form a RJV. If public funds are not too costly, lump-sum subsidies are a more efficient means to screen out the state $(\mathrm{L}, \mathrm{L})$. The expected subsidy compensates the low spillover firm for revealing truthfully. However, these lump-sum subsidies will not improve allocative efficiency of R\&D at the margin. They only improve the screening capability of the government. Examining a two-part subsidy scheme with a fixed transfer and a per unit R\&D subsidy is left for future research. The per unit R\&D subsidies improve total welfare both in the case of $R \& D$ cooperation and competition. But we still expect to find similar distortions of the first-best R\&D policy as in the case of lump-sum subsidies analyzed here.

The fact that rival firms can have different spillovers in the same industry, however small the probability, results in a non trivial R\&D policy. The first-best policy cannot be implemented anymore. Any rational firm will claim to have a high spillover level in the hope to be allowed to form a RJV. In reality the types of the firms will most likely be positively correlated $(0<\rho<1)$ within a given industry. Unlike an unsophisticated R\&D policy where the regulator only allows RJVs or not based on its 
beliefs about the state of the industry, the second-best R\&D policy uses the fact that the spillovers of the firms are correlated in its formulation. If the marginal probability of the low spillover type, $\theta$, is low, RJVs should always be allowed because the state $(H, H)$ is very likely. With a high marginal probability of the low spillover type, RJVs should not be allowed. As the correlation between the types increases, the regulator can use this correlation to improve upon the unsophisticated R\&D policy by punishing asymmetric state reports by the firms. A low spillover firm will then refrain from lying. A carefully structured lump-sum subsidy program gets the second-best R\&D policy even closer to the first-best.

The second-best R\&D policy derived in this paper differs from the current R\&D policy with respect to RJVs in both the US and Europe. We find that the regulator should worry more about the effects of asymmetric information between himself and the industry. What really drives the case for allowing RJVs is the existence of technological spillovers. The regulator can improve upon the existing R\&D policy of basically not challenging any RJV, by relying on its beliefs about the spillover state of the industry or, in some cases, screening for the true spillover state. Thus increasing scrutiny over RJV formation should increase welfare.

\section{Acknowledgements}

I would like to thank my advisors David Besanko and Pierre Regibeau for many helpful discussions and comments. I am also grateful to Jim Dana, Patrick Greenlee, Asher Wolinsky, the Editor and two anonymous referees for their comments and suggestions. Any remaining errors are mine. This paper is a revised version of Chapter 2 of my dissertation at the Department of Managerial Economics and Decision Sciences of the J.L. Kellogg Graduate School of Management, Northwestern University. Financial Assistance of the National Fund for Scientific Research of Belgium is gratefully acknowledged. 


\section{Appendix A}

From (A1) - (A4) we can immediately derive the following result:

Lemma 1: At the optimal mechanism either IC(L) is binding or IC(L) and $\mathrm{IC}(\mathrm{H})$ are both binding.

Proof: Just plug in the first-best mechanism:

IC(L) becomes: $v_{\mathrm{LL}} \leq 0$, which is clearly violated by (A4).

$\mathrm{IC}(\mathrm{H})$ becomes: $-\mathrm{v}_{\mathrm{HL}} \leq 0$ which is satisfied by (A4).

Thus IC(L) will have to be binding at the second best mechanism.

This obvious result will guide our solution process. First we solve for the optimal mechanism supposing that IC(L) is the only binding constraint. Afterwards we check for conditions such that $\mathrm{IC}(\mathrm{H})$ holds. If these conditions are violated we solve the model for the region where $\mathrm{IC}(\mathrm{H})$ is violated such that both constraints are binding.

To simplify the exposition define: $\alpha=\frac{p_{L L}}{p_{L H}}, \gamma=\frac{p_{H H}}{p_{L H}}$ and define the following critical

cutoffs:

$$
\bar{\alpha}=\frac{v_{L H}}{v_{L L}}, \hat{\alpha}=\frac{v_{L H} w_{L L}-2 v_{L L} w_{L H}}{v_{L L} w_{L L}}, \hat{\gamma}=-\frac{v_{L H} w_{L L}}{v_{L L} w_{H H}} .
$$

It is easy to show that $\bar{\alpha} \leq \hat{\alpha}$ when (A3) and (A4) hold. ${ }^{25}$

These cutoffs define five important regions in the $(\alpha, \gamma)$-belief space:

$$
\begin{aligned}
& R_{(1)}=\left\{(\alpha, \gamma) \in \mathfrak{R}_{+}^{2} \mid \alpha \leq \hat{\alpha}, \gamma \geq \hat{\gamma}\right\}, R_{(2)}=\left\{(\alpha, \gamma) \in \mathfrak{R}_{+}^{2} \mid \alpha \geq \hat{\alpha}, \gamma \leq \hat{\gamma}\right\}, \\
& R_{(3)}=\left\{(\alpha, \gamma) \in \mathfrak{R}_{+}^{2} \mid \alpha \geq \hat{\alpha}, \gamma \geq \hat{\gamma}\right\}, R_{(4)}=\left\{(\alpha, \gamma) \in \mathfrak{R}_{+}^{2} \mid \hat{\alpha} \geq \alpha \geq \bar{\alpha}, \gamma \leq \hat{\gamma}\right\}, \\
& R_{(5)}=\left\{(\alpha, \gamma) \in \mathfrak{R}_{+}^{2} \mid \alpha \leq \bar{\alpha}, \gamma \leq \hat{\gamma}\right\} .
\end{aligned}
$$

In the first case subsidies are zero and the R\&D policy simplifies to $f\left(\beta_{i}, \beta_{j}\right)=r_{\beta_{i} \beta_{j}}$. We can now make the formulation of the second-best R\&D policy of Proposition 1 and 2 precise. Note that given our definitions $\mathrm{U}\left(\mathrm{p}_{\mathrm{LL}}, \mathrm{p}_{\mathrm{HH}}\right) \propto \mathrm{U}(\alpha, \gamma)$ :

${ }^{25} \alpha=\frac{\rho+\frac{\theta}{1-\theta}}{1-\rho}$ and $\gamma=\frac{\rho+\frac{1-\theta}{\theta}}{1-\rho}$ 
Proposition 1 and 2:

Let

$$
\begin{aligned}
& I H_{(3)}=R_{(3)} \cap\left\{(\alpha, \gamma) \in \mathfrak{R}_{+}^{2} \mid \alpha \gamma \leq \frac{v_{L H} v_{H L}}{v_{L L} v_{H H}}\right\}, \\
& I H_{(4)}=R_{(4)} \cap\left\{(\alpha, \gamma) \in \Re_{+}^{2} \mid \alpha \gamma \geq \frac{v_{L H} v_{H L}}{v_{L L} v_{H H}}\right\} \\
& \text { and } I H_{(5)}=R_{(5)} \cap\left\{(\alpha, \gamma) \in \mathfrak{R}_{+}^{2} \mid \alpha \gamma \geq \frac{v_{L H} v_{H L}}{v_{L L} v_{H H}}\right\} .
\end{aligned}
$$

The second best mechanism, $\mathrm{f}^{\mathrm{SB}}$, is as follows:

(1) if $(\alpha, \gamma) \in \mathrm{R}_{(1)}$ then $r_{L L}^{S B}=1, r_{L H}^{S B}=1, r_{H H}^{S B}=1$.

(2) if $(\alpha, \gamma) \in \mathrm{R}_{(2)}$ then $r_{L L}^{S B}=0, r_{L H}^{S B}=0, r_{H H}^{S B}=0$.

(3) if $(\alpha, \gamma) \in \mathrm{R}_{(3)} \backslash \mathrm{IH}_{(3)}$ then $r_{L L}^{S B}=\frac{\bar{\alpha}}{\alpha}, r_{L H}^{S B}=0, r_{H H}^{S B}=1$.

(3') if $(\alpha, \gamma) \in \mathrm{IH}_{(3)}$ then if $\mathrm{U}(\alpha, \gamma) \geq 0$, then $r_{\beta_{i} \beta_{j}}^{S B}=1 \forall \beta_{k} \in\{L, H\}$,

$$
\text { if } \mathrm{U}(\alpha, \gamma) \leq 0 \text {, then } r_{\beta_{\beta} \beta_{j}}^{S B}=0 \quad \forall \beta_{k} \in\{L, H\} \text {. }
$$

(4) if $\left.(\alpha, \gamma) \in \mathrm{R}_{(4)}\right) \mathrm{IH}_{(4)}$ then $\quad r_{L L}^{S B}=1-\frac{\bar{\alpha}}{\alpha}, r_{L H}^{S B}=1, r_{H H}^{S B}=0$.

(4') if $(\alpha, \gamma) \in \mathrm{IH}_{(4)}$ then if $\mathrm{U}(\alpha, \gamma) \geq 0$, then $r_{\beta_{i} \beta_{j}}^{s B}=1 \quad \forall \beta_{k} \in\{L, H\}$,

$$
\text { if } \mathrm{U}(\alpha, \gamma) \leq 0 \text {, then } r_{\beta_{i} \beta_{j}}^{S B}=0 \quad \forall \beta_{k} \in\{L, H\} \text {. }
$$

(5) if $(\alpha, \gamma) \in \mathrm{R}_{(5)} \backslash \mathrm{IH}_{(5)}$ then $\quad r_{L L}^{S B}=0, r_{L H}^{S B}=1, r_{H H}^{S B}=1-\frac{\alpha}{\bar{\alpha}}$.

$\left(5^{\prime}\right)$ if $(\alpha, \gamma) \in \mathrm{IH}_{(5)}$ then if $\mathrm{U}(\alpha, \gamma) \geq 0$, then $r_{\beta_{i} \beta_{j}}^{S B}=1 \quad \forall \beta_{k} \in\{L, H\}$,

$$
\text { if } \mathrm{U}(\alpha, \gamma) \leq 0 \text {, then } r_{\beta_{i} \beta_{j}}^{S B}=0 \quad \forall \beta_{k} \in\{L, H\} \text {. }
$$

\section{PROOF:}

In a first step the problem is solved by assuming $\mathrm{IC}(\mathrm{L})$ is the only binding constraint. In a following step Lemma 2 derives when IC(L) is the only binding constraint and Lemma 3 derives what happens if both $\mathrm{IC}(\mathrm{L})$ and $\mathrm{IC}(\mathrm{H})$ are binding.

\section{STEP 1:}

Given that IC $(\mathrm{L})$ is binding, we can rewrite it as follows:

$$
r_{L L}=\left(1-\frac{\bar{\alpha}}{\alpha}\right) r_{L H}+\frac{\bar{\alpha}}{\alpha} r_{H H} .
$$

Substituting this into the regulator's objective gives: 


$$
\left[\left(1-\frac{\bar{\alpha}}{\alpha}\right) \alpha w_{L L}+2 w_{L H}\right] r_{L H}+\left[\bar{\alpha} w_{L L}+\gamma w_{H H}\right] r_{H H} .
$$

Note that $\mathrm{w}_{\mathrm{LL}}$ is negative $(\mathrm{A} 1)$.

We examine the coefficients of $r_{\mathrm{LH}}$ and $\mathrm{r}_{\mathrm{HH}}$ in order to maximize the objective.

Coefficient of $\mathrm{r}_{\underline{\underline{L}}}$ :

If $\alpha \leq \frac{v_{L H}}{v_{L L}}=\bar{\alpha}$, the coefficient of $\mathrm{r}_{\mathrm{LH}}$ is positive by (A1) and (A3). This implies that we want to increase $r_{\mathrm{LH}}$ to its maximum value, $\mathrm{r}_{\mathrm{LH}}=1$.

The coefficient of $\mathrm{r}_{L H}$ is still positive if $\alpha \geq \hat{\alpha}$ and $\alpha \leq \frac{v_{L H} w_{L L}-2 v_{L L} w_{L H}}{v_{L L} w_{L L}}=\hat{\alpha}$.

Coefficient of $\underline{r}_{\underline{H H}}$ :

If $\gamma \geq-\frac{v_{L H} w_{L L}}{v_{L L} w_{H H}}=\hat{\gamma}$, the coefficient of $\mathrm{r}_{\mathrm{HH}}$ is positive. Maximizing the objective function implies setting $\mathrm{r}_{\mathrm{HH}}=1$.

In $\mathrm{R}_{(1)}: \mathrm{r}_{\mathrm{LH}}=1, \mathrm{r}_{\mathrm{HH}}=1$, Substitution gives: $\mathrm{r}_{\mathrm{LL}}=1$.

In $R_{(2)}: r_{L H}=0, r_{H H}=0$, Substitution gives: $r_{L L}=0$.

In $\mathrm{R}_{(3)}: \mathrm{r}_{\mathrm{LH}}=0, \mathrm{r}_{\mathrm{HH}}=1$, Substitution gives: $\mathrm{r}_{\mathrm{LL}}=\frac{\bar{\alpha}}{\alpha}$

In $\mathrm{R}_{(4)}: \mathrm{r}_{\mathrm{LH}}=1, \mathrm{r}_{\mathrm{HH}}=0$, Substitution gives: $\mathrm{r}_{\mathrm{LL}}=1-\frac{\bar{\alpha}}{\alpha}$

In $\mathrm{R}_{(5)}: \mathrm{r}_{\mathrm{LH}}=1$,

Coefficient of $r_{H H}$ is negative. Setting $r_{H H}=0$, however, results in $r_{L L}<0$ !

Set $r_{L L}=0$ and solve for the minimal value of $r_{H H}$ for which IC(L) is satisfied:

$\mathrm{r}_{\mathrm{HH}}=1-\frac{\alpha}{\bar{\alpha}}$.

STEP 2:

We still need to check if $\mathrm{IC}(\mathrm{H})$ is satisfied in all these cases.

In regions $R_{(1)}$ and $R_{(2)}, I C(H)$ is trivially satisfied. The following Lemma states the conditions in the other cases.

Lemma 2:

$\mathrm{IC}(\mathrm{H})$ holds in region $\mathrm{R}_{(3)}$ if and only if $\forall(\alpha, \gamma) \in R_{(3)}: \quad \alpha \gamma \geq \frac{v_{L H} v_{H L}}{v_{L L} v_{H H}}$.

IC $(\mathrm{H})$ holds in region $\mathrm{R}_{(4)}$ if and only if $\forall(\alpha, \gamma) \in R_{(4)}: \quad \alpha \gamma \leq \frac{v_{L H} v_{H L}}{v_{L L} v_{H H}}$.

$\mathrm{IC}(\mathrm{H})$ holds in region $\mathrm{R}_{(5)}$ if and only if $\forall(\alpha, \gamma) \in R_{(5)}: \quad \alpha \gamma \leq \frac{v_{L H} v_{H L}}{v_{L L} v_{H H}}$.

Proof: Straight forward. Just write out $\mathrm{IC}(\mathrm{H})$ in every case. 
The conditions for regions $\mathrm{R}_{(3)}$, and, $\mathrm{R}_{(4)}$ and $\mathrm{R}_{(5)}$ are exactly opposite. Note that if $\mathrm{IH}_{(3)}$ $\neq \phi$ then $\mathrm{IH}_{(4)}=\phi=\mathrm{IH}_{(5)}$. If $\mathrm{IH}_{(4)} \neq \phi$ then $\mathrm{IH}_{(3)}=\phi$. $\mathrm{IH}_{(5)}$ can be empty or non-empty depending on the parameters. In region $\mathrm{R}_{(3)}$, when $\mathrm{IC}(\mathrm{H})$ is violated, the high type is tempted to lie if he believes that his competitor is of the low type, in which case if he tells the truth, they will not be allowed to form a RJV. In region $\mathrm{R}_{(4)}$ or $\mathrm{R}_{(5)}$, when $\mathrm{IC}(\mathrm{H})$ is violated, the high type would consider lying if he believes that his rival is also of the high type, since if the report is $(\mathrm{H}, \mathrm{H})$ they will not be allowed to form a RJV or only form a RJV with small probability.

Lemma 3: If both IC(L) and IC(H) are binding then $r_{\beta_{i} \beta_{j}}^{S B}=0 \quad \forall \beta_{k} \in\{L, H\}$ or $r_{\beta_{i} \beta_{j}}^{S B}=1 \forall \beta_{k} \in\{L, H\}$ in that region.

Proof: $\mathrm{IC}(\mathrm{L})$ and $\mathrm{IC}(\mathrm{H})$ are both binding.

Solve IC(L) for $\mathrm{r}_{\mathrm{LL}}: \quad r_{L L}^{S B}=\left(1-\frac{\bar{\alpha}}{\alpha}\right) r_{L H}+\frac{\bar{\alpha}}{\alpha} r_{H H}$.

Substitute into $\mathrm{IC}(\mathrm{H}) . \mathrm{IC}(\mathrm{H})$ is binding if and only if

$$
\left[\frac{v_{H L} v_{L H}}{v_{L L} v_{H H}}-\alpha \gamma\right]\left[r_{H H}-r_{L H}\right]=0 .
$$

So either $\mathrm{r}_{\mathrm{LH}}=\mathrm{r}_{\mathrm{HH}}$ or $\alpha \gamma=\frac{v_{H L} v_{L H}}{v_{L L} v_{H H}}$.

The second condition exactly indicates the border of the region where $\mathrm{IC}(\mathrm{H})$ will be violated (Lemma 2). Substituting $r_{L H}=r_{H H}$ into the formula for $r_{L L}$ gives us $r_{L L}=r_{L H}=r_{H H}$.

In the regions where both IC constraints are binding, we have to compare the policy where no RJVs are allowed to the case of always allowing a RJV which is equivalent to checking :

$$
\operatorname{sign}\left[\mathrm{p}_{\mathrm{LL}} \mathrm{w}_{\mathrm{LL}}+2 \mathrm{p}_{\mathrm{LH}} \mathrm{w}_{\mathrm{LH}}+\mathrm{p}_{\mathrm{HH}} \mathrm{w}_{\mathrm{HH}}\right]=\operatorname{sign} \mathrm{U}\left(\mathrm{p}_{\mathrm{LL}}, \mathrm{p}_{\mathrm{HH}}\right) \propto \mathrm{U}(\alpha, \gamma) .
$$

If $\mathrm{U}(\alpha, \gamma)$ is positive in that specific region, then RJVs should always be allowed.

In the statement of the Proposition the regions $\mathrm{IH}_{(\mathrm{x})}$ coincide with regions where $\mathrm{IC}(\mathrm{H})$ is violated, while in the regions $\mathrm{R}_{(\mathrm{x})} \backslash \mathrm{IH}_{(\mathrm{x})}$ only IC(L) is binding. $\square$

Proof of Proposition 3

A simple exercise in differentiation.

Note that $q=\frac{p_{L H} v_{L H}}{p_{L L} v_{L L}}=\frac{(1-\theta)(1-\rho)}{\theta+\rho(1-\theta)} \frac{v_{L H}}{v_{L L}}$,

$\frac{\partial q}{\partial \rho}=\frac{-(1-\theta) v_{L H}}{(\theta+\rho(1-\theta))^{2} v_{L L}} \leq 0$ and $\frac{\partial q}{\partial \theta}=\frac{-(1-\rho) \theta v_{L H}}{(\theta+\rho(1-\theta))^{2} v_{L L}} \leq 0$. 
In order to state Proposition 5 precisely, define $\bar{\alpha}, \hat{\alpha}, \hat{\gamma}$ as before, and let:

$$
\lambda^{*}=\frac{-w_{L L}}{2 v_{L L}}, \hat{\alpha}(\lambda)=\frac{w_{L H}+\lambda v_{L H}}{\lambda v_{L L}}, \hat{\gamma}(\lambda)=\frac{2 \lambda v_{L H}}{w_{H H}} .
$$

It is easy to show that: $\hat{\alpha}(\lambda) \geq \hat{\alpha} \quad \forall \lambda \leq \lambda^{*}$ and $\lim _{\lambda \rightarrow \lambda^{*}} \hat{\alpha}(\lambda)=\hat{\alpha}$, and

$$
\hat{\gamma}(\lambda) \leq \hat{\gamma} \quad \forall \lambda \leq \lambda^{*} \text { and } \lim _{\lambda \rightarrow \lambda^{*}} \hat{\gamma}(\lambda)=\hat{\gamma}
$$

These cutoffs define five important regions in $(\alpha, \gamma)$-belief space:

$$
\begin{aligned}
& R \lambda_{(1)}=\left\{(\alpha, \gamma) \in \mathfrak{R}_{+}^{2} \mid \alpha \leq \hat{\alpha}(\lambda), \gamma \geq \hat{\gamma}(\lambda)\right\}, \\
& R \lambda_{(2)}=\left\{(\alpha, \gamma) \in \mathfrak{R}_{+}^{2} \mid \alpha \geq \hat{\alpha}(\lambda), \gamma \leq \hat{\gamma}(\lambda)\right\}, \\
& R \lambda_{(3)}=\left\{(\alpha, \gamma) \in \mathfrak{R}_{+}^{2} \mid \alpha \geq \hat{\alpha}(\lambda), \gamma \geq \hat{\gamma}(\lambda)\right\}, \\
& R \lambda_{(4)}=\left\{(\alpha, \gamma) \in \mathfrak{R}_{+}^{2} \mid \hat{\alpha}(\lambda) \geq \alpha \geq \bar{\alpha}, \gamma \leq \hat{\gamma}(\lambda)\right\}, \\
& R \lambda_{(5)}=\left\{(\alpha, \gamma) \in \mathfrak{R}_{+}^{2} \mid \alpha \leq \bar{\alpha}, \gamma \leq \hat{\gamma}(\lambda)\right\} .
\end{aligned}
$$

\section{Proof of Proposition 4}

See proof of Proposition 5.

Proposition 5: Suppose $\lambda \leq \lambda^{*}$. When only $\mathrm{IC}(\mathrm{L})$ is binding, the second best mechanism, $\mathrm{f}^{\mathrm{SB}}$, is as follows:

(1) if $(\alpha, \gamma) \in \mathrm{R} \lambda_{(1)}$ then $f^{S B}(L, L)=\left[0, S_{L L}^{l}, S_{L L}^{2}\right], f^{S B}(L, H)=\left[1, S_{L H}^{l}, 0\right]$,

$$
f^{S B}(H, L)=\left[1,0, S_{L H}^{2}\right], f^{S B}(H, H)=[1,0,0] \text {, where } \alpha S_{L L}^{i}+S_{L H}^{i}=\alpha v_{L L} \text {. }
$$

(2) if $(\alpha, \gamma) \in \mathrm{R} \lambda_{(2)}$ then $\mathrm{f}^{\mathrm{SB}}\left(\beta_{\mathrm{i}}, \beta_{\mathrm{j}}\right)=[0,0,0], \forall \beta_{\mathrm{k}} \in\{\mathrm{L}, \mathrm{H}\}$.

(3) if $(\alpha, \gamma) \in \mathrm{R} \lambda_{(3)}$ then $f^{S B}(L, L)=\left[0, S_{L L}^{l}, S_{L L}^{2}\right], f^{S B}(L, H)=\left[0, S_{L H}^{l}, 0\right]$,

$$
f^{S B}(H, L)=\left[0,0, S_{L H}^{2}\right], f^{S B}(H, H)=[1,0,0] \text {, where } \alpha S_{L L}^{i}+S_{L H}^{i}=v_{L H} .
$$

(4) if $(\alpha, \gamma) \in \mathrm{R} \lambda_{(4)}$ then $f^{S B}(L, L)=\left[0, S_{L L}^{l}, S_{L L}^{2}\right], f^{S B}(L, H)=\left[1, S_{L H}^{l}, 0\right]$,

$$
\begin{aligned}
f^{S B}(H, L)= & {\left[1,0, S_{L H}^{2}\right], f^{S B}(H, H)=[0,0,0], } \\
& \text { where } \alpha S_{L L}^{i}+S_{L H}^{i}=\alpha v_{L L}-v_{L H} .
\end{aligned}
$$

(5) if $(\alpha, \gamma) \in \mathrm{R} \lambda_{(5)}$ then $f^{S B}(L, L)=[0,0,0], f^{S B}(L, H)=f^{S B}(H, L)=[1,0,0]$,

$$
f^{S B}(H, H)=\left[1-\frac{\alpha}{\bar{\alpha}}, 0,0\right] \text {. }
$$

\section{PROOF:}


We take the same approach as in the proof of Propositions 1 and 2. In STEP 1 the model is solved while assuming that only IC $(\mathrm{L})$ is binding, while in STEP 2 we check if and when $\mathrm{IC}(\mathrm{H})$ is satisfied.

\section{STEP 1:}

Subsidies decrease the expected welfare. Setting $\mathrm{S}_{\mathrm{HL}}$ and $\mathrm{S}_{\mathrm{HH}}$ equal to zero does not hurt the IC(L). Given that IC(L) is binding we can then rewrite it:

$$
\alpha S_{L L}+S_{L H}=-\alpha v_{L L} r_{L L}+\alpha v_{L L}\left(1-\frac{\bar{\alpha}}{\alpha}\right) r_{L H}+v_{L H} r_{H H} .
$$

Substitute into the objective function:

$\alpha\left[w_{L L}+2 \lambda v_{L L}\right] r_{L L}+2\left[w_{L H}-\alpha \lambda v_{L L}\left(1-\frac{\bar{\alpha}}{\alpha}\right)\right] r_{L H}+\left[\gamma_{w_{H H}}-2 \lambda v_{L L} \frac{\bar{\alpha}}{\alpha}\right] r_{H H}$

Again we check the coefficients of the decision variables.

\section{Coefficient of $\mathrm{r}_{\underline{L L}}$ :}

The coefficient of $r_{L L}$ is positive if and only if $\lambda \geq \frac{-w_{L L}}{2 v_{L L}}=\lambda^{*}$.

Coefficient of $\mathrm{r}_{\mathrm{LH}}$ :

The coefficient of $r_{L H}$ is positive if and only if $\quad \alpha \leq \frac{w_{L H}+\lambda v_{L H}}{\lambda v_{L L}}=\hat{\alpha}(\lambda)$.

Set $r_{L H}=1$ if this holds.

Coefficient of $\mathrm{r}_{\mathrm{HH}}$ :

The coefficient of $r_{H H}$ is positive if and only if $\gamma \geq \frac{2 \lambda v_{L H}}{w_{H H}}=\hat{\gamma}(\lambda)$.

Set $\mathbf{r}_{\mathrm{HH}}=1$ if this holds.

If the coefficient of $r_{L L}$ is positive, it is easy to show that the expected subsidy to the low spillover type is non positive: $\alpha \mathrm{S}_{\mathrm{LL}}+\mathrm{S}_{\mathrm{LH}} \leq 0$. With non-negative subsidies, this implies that $S_{\mathrm{LL}}=0$ and $\mathrm{S}_{\mathrm{LH}}=0$. We are now back in the no-subsidy case. This proves Proposition 4: if the cost of public funds is high, no subsidies are used.

In $R \lambda_{(1)}: r_{L L}=0, r_{L H}=1, r_{H H}=1$, Substitution in IC(L) gives: $\alpha S_{L L}+S_{L H}=\alpha v_{L L}$.

In $R \lambda_{(2)}: r_{L L}=0, r_{L H}=0, r_{H H}=0, S_{L L}=0$ and $S_{L H}=0$.

In $R \lambda_{(3)}: r_{L L}=0, r_{L H}=0, r_{H H}=1$, Substitution in IC(L) gives: $\alpha S_{L L}+S_{L H}=v_{L H}$.

In $\mathrm{R} \lambda_{(4)}: \mathrm{r}_{\mathrm{LL}}=0, \mathrm{r}_{\mathrm{LH}}=1, \mathrm{r}_{\mathrm{HH}}=0$,

Substitution in IC(L) gives: $\alpha \mathrm{S}_{\mathrm{LL}}+\mathrm{S}_{\mathrm{LH}}=\alpha \mathrm{v}_{\mathrm{LL}}-\mathrm{v}_{\mathrm{LH}}$.

In $\mathrm{R} \lambda_{(5)}: \mathrm{r}_{\mathrm{LL}}=0, \mathrm{r}_{\mathrm{LH}}=1, \mathrm{r}_{\mathrm{HH}}=1-\frac{\alpha}{\bar{\alpha}}, \mathrm{S}_{\mathrm{LL}}=0$ and $\mathrm{S}_{\mathrm{LH}}=0$. 


\section{STEP 2:}

Again we need to check for conditions when $\mathrm{IC}(\mathrm{H})$ is satisfied.

A straightforward exercise in plugging the results of different regions into $\mathrm{IC}(\mathrm{H})$ gives us the following conditions to be satisfied:

(AA1). IC(H) holds in $\mathrm{R} \lambda_{(1)}$ if and only if $\alpha\left(v_{L L}-v_{H L}\right)+(\alpha \gamma-1) S_{L H} \leq 0$.

(AA2). IC(H) holds in $\mathrm{R} \lambda_{(3)}$ if and only if $v_{L H}-\alpha \gamma v_{H H}+(\alpha \gamma-1) S_{L H} \leq 0$.

(AA3). $\mathrm{IC}(\mathrm{H})$ holds in $\mathrm{R} \lambda_{(4)}$ if and only if

$$
\alpha\left(v_{L L}-v_{H L}\right)+\alpha \gamma v_{H H}-v_{L H}+(\alpha \gamma-1) S_{L H} \leq 0 \text {. }
$$

To simplify the exposition for this case, we make the following assumptions:

A5: $\quad \hat{\gamma} \leq \frac{v_{L L}}{v_{H H}}$,

A6: $\quad \mathrm{v}_{\mathrm{HL}} \geq \mathrm{v}_{\mathrm{LL}}$,

A7: $\quad \mathrm{v}_{\mathrm{HH}} \geq \mathrm{v}_{\mathrm{LH}}$,

A8: $\quad \hat{\gamma} \leq \frac{v_{H L}-v_{L L}}{v_{H H}-v_{L H}}$,

A8': $\quad \hat{\alpha}(\lambda) \hat{\gamma}(\lambda) \leq 1$.

Assumption (A5) comes straight from Lemma 2 and guarantees that $\mathrm{IC}(\mathrm{H})$ is not binding in region $\mathrm{R}_{(5)}$. Assumption (A6) states that the profit gains from forming a RJV for the high type are larger than that of a low type when the rival is of the low type and (A7) is a similar statement if the rival is a high type. Both (A6) and (A7) imply that regardless of the competitor's type, the gains from $R \& D$ cooperation for the high spillover type are larger than those of a low spillover type. The rival of a high spillover firm will reduce its $R \& D$ expenditures significantly, since he loses everything to the high spillover firm. By forming a RJV, this externality is internalized and R\&D investments increase. This benefits the high spillover firm in particular. These assumptions formulate the traditional single crossing property for this model. Assumptions (A8) and (A8') are made to simplify the exposition (see Appendix B). Since $\hat{\gamma}^{*}(\lambda) \leq \hat{\gamma}^{*}$, assumption (A8) implies that $\hat{\gamma}^{*}(\lambda)$ is low. A firm with a high spillover will place high probability on the event that his rival is of the low type.

Lemma 4: $\quad$ If (A1)-(A8') hold, then $\mathrm{IC}(\mathrm{H})$ is always satisfied.

Proof: * Set $\mathrm{S}_{\mathrm{LH}}=0$. (AA1) is immediately satisfied if (A6) holds.

$*$ Set $\mathrm{S}_{\mathrm{LH}}=\mathrm{v}_{\mathrm{LH}}$ (AA2) is immediately satisfied if (A7) holds.

* Set $\mathrm{S}_{\mathrm{LH}}=0$. From $\left(\mathrm{A} 88^{\prime}\right)$ we know that $\alpha \gamma \leq 1$ for all $(\alpha, \gamma)$ in $\mathrm{R} \lambda_{(4)}$.

$(\mathrm{AA} 3) \leq \alpha \gamma\left[\mathrm{v}_{\mathrm{HH}}-\mathrm{v}_{\mathrm{LH}}\right]+\alpha\left[\mathrm{v}_{\mathrm{LL}}-\mathrm{v}_{\mathrm{HL}}\right]$,

(A8) insures that this expression is still less than zero.

* If (A5) holds, then $\mathrm{IC}(\mathrm{H})$ is satisfied in region 5, from Lemma 2. 
With the assumptions (A5)-(A8') made in STEP 2, only IC(L) is binding and the results of STEP 1 determine the second-best policy.

\section{Appendix B}

In this Appendix we show that all assumptions made in the general model are satisfied in a simple, but often used model of $R \& D$ investment with spillovers. We focus on the cost reducing investment game proposed by d'Aspremont and Jacquemin (1988). The game firms play is a two stage game. In the first stage they make R\&D investment decisions to reduce their marginal costs of production in the second stage. In the second stage firms compete in quantities in the output market. Spillovers through which knowledge (part of the firms investment) is also acquired by the rival firm, occur in the first stage. After the first stage firms observe each others R\&D levels. ${ }^{26}$ Let $\mathrm{x}_{\mathrm{i}}$ be firm i's first stage $R \& D$ investment and $q_{i}$ its second stage market output. Let $M C_{i}$ be firm i's marginal cost of production: $\mathrm{MC}_{\mathrm{i}}=\mathrm{c}-\mathrm{x}_{\mathrm{i}}-\beta_{\mathrm{i}} \mathrm{x}_{\mathrm{j}}$ where $\beta_{\mathrm{i}}=\mathrm{L}=0$ or $\beta_{\mathrm{i}}=\mathrm{H}=1$. Firms products are homogeneous with demand, $\mathrm{p}=\mathrm{a}-\mathrm{Q}$, where $\mathrm{Q}=\mathrm{q}_{1}+\mathrm{q}_{2}$ and $\mathrm{a}>\mathrm{c}$.

We now append a stage to the game before the firms make any decisions. In this stage the regulator sets up the mechanism where it allows RJVs or not depending on the firms reports and can give a lump sum subsidy. Profits and welfare will depend on the institutional mechanism set up by the regulator. To simplify notation we will index all functions by nc when firms act non-cooperatively in both stages and $\mathbf{c}$ when a RJV is formed. ${ }^{27}$

To obtain a subgame perfect equilibrium, we solve the game backwards. Firms always act non-cooperatively (Nash-Cournot) in the output market (suppose this is enforced by antitrust legislation). We can solve for the output levels as a function of $R \& D$ investment levels in the first stage:

$\mathrm{q}_{\mathrm{i}}\left(\mathrm{x}_{\mathrm{i}}, \mathrm{x}_{\mathrm{j}} ; \beta_{\mathrm{i}}, \beta_{\mathrm{j}}\right)=\mathrm{Z}+\mathrm{A}_{\mathrm{i}} \mathrm{x}_{\mathrm{i}}+\mathrm{B}_{\mathrm{i}} \mathrm{x}_{\mathrm{j}}$, where $\mathrm{Z}=(\mathrm{a}-\mathrm{c}) / 3, \mathrm{~A}_{\mathrm{i}}=\left(2-\beta_{\mathrm{j}}\right) / 3$ and $\mathrm{B}_{\mathrm{i}}=\left(2 \beta_{\mathrm{i}}-1\right) / 3$. note that $A_{i}>0 \forall \beta_{i}$ and $B_{i}<0$ if $\beta_{i}=0, B_{i}>0$ if $\beta_{i}=1$.

In the previous stage firms decide on $R \& D$ investment. Note that we assumed that at the time that the firms make their R\&D and output decisions they have perfect information about the state of nature. The regulator can influence this decision by its R\&D policy schedule that is set up in a stage before the firms play their two stage game.

Reduced form profits as a function of R\&D investments are:

$\mathrm{V}_{\mathrm{i}}^{\mathrm{k}}\left(\mathrm{x}_{\mathrm{i}}, \mathrm{x}_{\mathrm{j}} ; \beta_{\mathrm{i}}, \beta_{\mathrm{j}}\right)=\left[\mathrm{q}_{\mathrm{i}}\left(\mathrm{x}_{\mathrm{i}}, \mathrm{x}_{\mathrm{j}} ; \beta_{\mathrm{i}}, \beta_{\mathrm{j}}\right)\right]^{2}-(\Gamma / 2)\left(\mathrm{x}_{\mathrm{i}}\right)^{2}$ where $\mathrm{x}_{\mathrm{i}}=\mathrm{x}_{\mathrm{i}}^{\mathrm{k}}\left(\beta_{\mathrm{i}}, \beta_{\mathrm{j}}\right)$ and $\mathrm{k}=\mathrm{nc}$ or c,

${ }^{26}$ This assumption is to allow for strategic interactions w.r.t. R\&D (De Bondt and Veugelers (1991)).

${ }^{27}$ Forming a RJV in this model stands for maximizing joint profits in the R\&D stage. No efficiency gains in $R \& D$ are assumed. No new entity is necessarily created by this agreement. See also footnote 7. 
where $(\Gamma / 2)\left(\mathrm{x}_{\mathrm{i}}\right)^{2}$ is the cost function for R\&D investments accounting for decreasing returns to scale in $R \& D$. $\Gamma$ is an efficiency parameter: the lower $\Gamma$, the more efficient the firm in its $R \& D$ investments.

The equilibrium R\&D levels for the different cases are:

Firms compete in $R \& D$ :

$\mathrm{x}_{\mathrm{i}}^{\mathrm{nc}}\left(\beta_{\mathrm{i}}, \beta_{\mathrm{j}}\right)=\left[2 \mathrm{ZA}_{\mathrm{i}}\left(\Gamma-2 \mathrm{~A}_{\mathrm{j}}^{2}+2 \mathrm{~A}_{\mathrm{j}} \mathrm{B}_{\mathrm{i}}\right)\right] / \mathrm{N}, \quad$ where $\mathrm{N}=\left(\Gamma-2 \mathrm{~A}_{\mathrm{i}}^{2}\right)\left(\Gamma-2 \mathrm{~A}_{\mathrm{j}}^{2}\right)-\left(2 \mathrm{~A}_{\mathrm{i}} \mathrm{B}_{\mathrm{i}}\right)\left(2 \mathrm{~A}_{\mathrm{j}} \mathrm{B}_{\mathrm{j}}\right)$.

Firms form a RJV:

$\mathrm{x}_{\mathrm{i}}^{\mathrm{c}}\left(\beta_{\mathrm{i}}, \beta_{\mathrm{j}}\right)=2 \mathrm{Z}\left[\left(\mathrm{A}_{\mathrm{j}}+\mathrm{B}_{\mathrm{i}}\right)\left(2 \mathrm{~A}_{1} \mathrm{~B}_{1}+2 \mathrm{~A}_{2} \mathrm{~B}_{2}\right)+\left(\mathrm{A}_{\mathrm{i}}+\mathrm{B}_{\mathrm{j}}\right)\left(\Gamma-2 \mathrm{~A}_{\mathrm{i}}^{2}-2 \mathrm{~B}_{\mathrm{j}}^{2}\right)\right] / \mathrm{M}$, where $\mathrm{M}=\left(\Gamma-2 \mathrm{~B}_{1}^{2}-2 \mathrm{~A}_{2}^{2}\right)\left(\Gamma-2 \mathrm{~A}_{1}^{2}-2 \mathrm{~B}_{2}^{2}\right)-\left(2 \mathrm{~A}_{1} \mathrm{~B}_{1}+2 \mathrm{~A}_{2} \mathrm{~B}_{2}\right)^{2}$

We assume that all output levels are non negative, the second order conditions are satisfied as well as the stability conditions on the problem (Seade (1980), Henriques (1990), d'Aspremont and Jacquemin (1990), De Bondt and Henriques (1992), De Bondt, Slaets and Cassiman (1992)). Basically this will put lower bounds on the R\&D efficiency parameter $\Gamma: \Gamma$ must be "sufficiently" large. From these conditions we derive that $\Gamma>\underline{\Gamma}=4 / 3 .^{28}$

The welfare function (consumer $\left(\mathrm{CS}^{\mathrm{k}}\right)$ plus producer surplus $\left.\left(\mathrm{V}_{1}{ }^{\mathrm{k}}+\mathrm{V}_{2}{ }^{\mathrm{k}}\right)\right)$ is:

$\mathrm{W}^{\mathrm{k}}\left(\beta_{\mathrm{i}}, \beta_{\mathrm{j}}\right)=\left(\mathrm{q}_{1}+\mathrm{q}_{2}\right)^{2} / 2+\left(\mathrm{q}_{1}^{2}+\mathrm{q}_{2}^{2}\right)-\Gamma / 2\left(\mathrm{x}_{1}^{2}+\mathrm{x}_{2}^{2}\right) \quad$ where $\mathrm{k}=\mathrm{nc}$ or $\mathrm{c}$.

Now we are able to calculate the reduced form profit and welfare functions gross of subsidies for all states for all possible government R\&D policies under perfect information. These are the objects we care about in the paper.

$$
\begin{aligned}
& W^{n c}(L, L)=\frac{4(a-c)^{2} \Gamma}{9 \Gamma-4} \\
& W^{n c}(L, H)=\frac{2(a-c)^{2}\left(162 \Gamma^{3}-261 \Gamma^{2}+132 \Gamma-16\right) \Gamma}{(9 \Gamma-4)^{2}(3 \Gamma-2)^{2}} \\
& W^{n c}(H, H)=\frac{4(a-c)^{2}(9 \Gamma-1) \Gamma}{(9 \Gamma-4)^{2}} \\
& W^{c}(L, L)=\frac{4(a-c)^{2}(9 \Gamma-1) \Gamma}{(9 \Gamma-2)^{2}} \\
& W^{c}(L, H)=\frac{2(a-c)^{2}(\Gamma-1)\left(18 \Gamma^{2}-23 \Gamma+4\right) \Gamma}{\left(9 \Gamma^{2}-14 \Gamma+4\right)^{2}} \\
& W^{c}(H, H)=\frac{4(a-c)^{2}(9 \Gamma-4) \Gamma}{(9 \Gamma-8)^{2}}
\end{aligned}
$$

$\overline{{ }^{28}}$ The exact conditions and calculations for this section are available upon request. 


$$
\begin{aligned}
V^{n c}(L, L) & =\frac{(a-c)^{2}(9 \Gamma-8) \Gamma}{(9 \Gamma-4)^{2}} \\
V^{n c}(L, H) & =\frac{(a-c)^{2}(3 \Gamma-4)^{2}(9 \Gamma-2) \Gamma}{(9 \Gamma-4)^{2}(3 \Gamma-2)^{2}} \\
V^{n c}(H, L) & =\frac{9(a-c)^{2}(9 \Gamma-8) \Gamma^{3}}{(9 \Gamma-4)^{2}(3 \Gamma-2)^{2}} \\
V^{n c}(H, H) & =\frac{(a-c)^{2}(9 \Gamma-2) \Gamma}{(9 \Gamma-4)^{2}}
\end{aligned}
$$

$$
\begin{aligned}
& V^{c}(L, L)=\frac{(a-c)^{2} \Gamma}{9 \Gamma-2} \\
& V^{c}(L, H)=\frac{(a-c)^{2}(\Gamma-2) \Gamma}{9 \Gamma^{2}-14 \Gamma+4} \\
& V^{c}(H, L)=\frac{(a-c)^{2} \Gamma^{2}}{9 \Gamma^{2}-14 \Gamma+4} \\
& V^{c}(H, H)=\frac{(a-c)^{2} \Gamma}{9 \Gamma-8}
\end{aligned}
$$

Proposition (B1): $\quad$ There exists a $\Gamma^{*}$ such that for all $\Gamma>\max \left\{\Gamma^{*}, \underline{\Gamma}\right\}$ the assumptions (A1)-(A4) are satisfied in this model.

Proof: Note that all reduced form profit and welfare functions are a function of $\Gamma$ and $(\mathrm{a}-\mathrm{c})^{2}$ and are separable in these terms. To check the assumptions it is sufficient to check the largest root $\Gamma^{(\mathrm{i})}$ of these expressions and check the sign of these expressions for larger $\Gamma$ : (A1) - (A3) hold for all $\Gamma>\underline{\Gamma}$

If transfers are allowed in the RJV, (A4) holds for all $\Gamma>\underline{\Gamma}$, since we assume that the firms forming a RJV will maximize joint profits. If no transfers are allowed, we could also focus on a particular split of the joint profits namely the one where no transfers are involved, each firm gets the profits according to its production when individual R\&D levels are chosen to maximize joint profits. Again we can derive the conditions on $\Gamma$ for (A4) to hold:

$$
\begin{aligned}
& \text { in states }(\mathrm{L}, \mathrm{L}),(\mathrm{H}, \mathrm{L}) \text { and }(\mathrm{H}, \mathrm{H}),(\mathrm{A} 4) \text { holds if } \Gamma>\underline{\Gamma} \text {. } \\
& \text { in state }(\mathrm{L}, \mathrm{H}),(\mathrm{A} 4) \text { holds if } \Gamma>\max \{3.36, \underline{\Gamma}\}=3.36 \text {. }
\end{aligned}
$$

Let $\Gamma^{*}=\underline{\Gamma}=4 / 9$ in the general case or let $\Gamma^{*}=3.36$ in the specific RJV profit sharing case.

Proposition (B2): $\quad$ For all $\Gamma>\underline{\Gamma}$ the assumptions (A5)-(A8') are satisfied in this model.

Proof: $\quad$ (A5) holds for all $\Gamma>\max \{1.06, \underline{\Gamma}\}=\underline{\Gamma}$

(A6) and (A7) hold for all $\Gamma>\max \{0.84, \underline{\Gamma}\}=\underline{\Gamma}$

(A8) holds for all $\Gamma>\max \{1.15, \underline{\Gamma}\}=\underline{\Gamma}$

(A8') holds for all $\Gamma>\max \{1.08, \underline{\Gamma}\}=\underline{\Gamma}$

\section{References}


Anton, J. and D. Yao, 1989, Split Awards, Procurement and Innovation, Rand Journal of Economics, 30, 538-552.

Arrow, K., 1962, Economic Welfare and the Allocation of Resources for invention, in The Rate and Direction of Inventive Activity, R.R Nelson (ed.), Princeton University Press, New York, p.609-625.

Audretsch, D., 1989, Joint R\&D and Industrial Policy in Japan, in Cooperative Research and Development: The Industry-University-Government Relationship, Link, A. and Tassey, G. eds., Dordrecht: Kluwer Academic Publishers.

Auriol, E and J.J. Laffont, 1992, Regulation by Duopoly, Journal of Economics and Management Strategy, 1, 3, p.

Baron, D., 1989, The Design of Regulatory Mechanisms and Institutions, Handbook of Industrial Organization, vol.II, Schmalensee, R. and R. Willig eds., North Holland, p.1346-1447.

Baron, D. and D. Besanko, 1992, Information, Control, and Organizational Structure, Journal of Economics \& Management Strategy, 1, p.237-375.

Baron, D. and R. Myerson, 1982, Regulating a Monopolist with unknown costs, Econometrica, 50, p.911-930.

Besanko, D.and D. Spulber, 1989, Antitrust Enforcement under Asymmetric Information, The Economic Journal, 99, p.408-425.

Besanko, D. and D. Spulber, 1993, Contested Merger and Equilibrium Antitrust Policy, Journal of Law, Economics and Organization, 9, p.1-29.

Brodley, J.F., 1990, Antitrust Law and Innovation Cooperation, Journal of Economic Perspectives, 4, p.97-112.

Brown, K.M., 1984, The Elusive Carrot: Tax Incentives for R\&D, Regulation, jan/feb, p.33-38.

Cohen, W.M. and D.A. Levinthal, 1989, Innovation and Learning: The two faces of R\&D, The Economic Journal, 99, p.569-596.

Cremer, J. and R. McLean, 1988, Full Extraction of the Surplus in Bayesian and Dominant Strategy Auctions, Econometrica, 56, p.1247-1257.

d'Aspremont, C. and A. Jacquemin, 1988, Cooperative and Noncooperative R\&D in Duopoly with Spillover, American Economic Review, 78, p.1133-1137.

d'Aspremont, C. and A. Jacquemin, 1990, Cooperative and Noncooperative R\&D in Duopoly with Spillover: Erratum, American Economic Review, 80, p.641-642.

De Bondt, R. and I. Henriques, 1995, Strategic Investment and Asymmetric Spillovers, Canadian Journal of Economics, XXVIII, p.656-674.

De Bondt, R., Slaets, P. and B. Cassiman, 1992, The Degree of Spillovers and the number of Rivals for Maximum Effective R\&D, International Journal of Industrial Organization, 10, p.35-54.

De Bondt, R. and R. Veugelers, 1991, Strategic Investment with Spillovers, European Journal of Political Economy, 7, p.345-366. 
De Bondt, R. and C. Wu, 1997, Research Joint Venture Cartels and Welfare, forthcoming in Poyago-Theotoky, J. (ed.), R\&D Cooperation: Theory and Practice, MacMillan, London.

Demski, J.S. and DEM Sappington, Optimal Incentive Contracts with Multiple Agents, Journal of Economic Theory, 33, p.152-171.

Fusfeld, H. and C. Haklish, 1985, Cooperative R\&D for Competitors, Harvard Business Review, Nov-Dec, p.60-76.

Geroski, P., 1992, Antitrust Policy towards Co-operative R\&D Ventures, Oxford Review of Economic Policy, 9, p.58-71.

Greenlee, P. and B. Cassiman, forthcoming, Firm Objectives and the Formation of Research Joint Ventures, in "Does Europe have an Industrial Policy?," D. Neven and L.H. Röller (eds.), Cambridge University Press, London.

Grossman, G. and C. Shapiro, 1986, Research Joint Ventures: An Antitrust Analysis, Journal of Law, Economics and Organization, 2, p.315-337.

Hagedoorn, J. and J. Schakenraad, 1992, Leading Companies and Networks of Strategic Alliances in Information Technologies, Research Policy, 21, p.163190.

Henriques, I., 1990, Cooperative and Noncooperative R\&D in Duopoly with Spillovers: Comment, American Economic Review, 80-3, p.638-640.

Jacquemin, A., 1988, Cooperative Agreements in R\&D and European Antitrust Policy, European Economic Review, 32, p.551-560.

Jacquemin, A. and Soete, L.,1994, Cooperation in R\&D, Efficiency and European Policy, European Review, 2, p.65-72.

Jorde, T. and D. Teece, 1990, Innovation and Cooperation: Implications for Competition and Antitrust, Journal of Economic Perspectives, 4, p.75-96.

Kamien, M., Muller, E. and I. Zang, 1992, Research Joint Ventures and R\&D Cartels, American Economic Review, 82, 5, p.1293-1306.

Katz, M.L., 1986, An Analysis of Cooperative Research and Development, RAND journal of Economics, 17-4, p.527-543.

Katz, M.L. and J.A. Ordover, 1990, R\&D Cooperation and Competition, Economic Activity, Brooking Papers: Microeconomics, p.137-203.

Kleinknecht, A. and J. Reijnen, 1992, Why do Firms Cooperate on R\&D? An Empirical Study, Research Policy, 21, p.347-360.

Laffont, J.J. and D. Martimort, 1997, Mechanism Design with Collusion and Correlation, mimeo.

Levin, R. and P. Reiss, 1988, Cost Reducing and Demand Creating R\&D with Spillovers, The Rand Journal of Economics, 19, p.538-556.

Link, A.N., 1996, Research Joint Ventures: Patterns from Federal Register Fillings, Review of Industrial Organization, 11, p.617-628.

Martin, S., 1993, Public Policy toward Cooperation in Research and Development: the European Community, Japan, the United States, working paper Department of Economics, European University Institute, Florence, mimeo. 
Martin, S., 1996, Protection, Promotion and Cooperation in the European Semiconductor Industry, Review of Industrial Organization, 11, p.721-735.

McGuire, T. and M. Riordan, 1991, Incomplete Information and Optimal Market Structure: Public Purchases from Public Providers, Mimeo, Boston University.

Odagiri, H., 1986, Industrial Policy in Theory and Reality, in Mainstreams in Industrial Organization Book II, de Jong, H. and Shepherd, W. eds., Dordrecht: Kluwer Academic Publishers.

Olsen, T.E., 1993, Regulation of Multi-agent Research and Development, RAND Journal of Economics, 24-4 winter, p.529-541.

Ordover, J. and R. Willig, 1985, Antitrust for High-Technology Industries: Assessing Research Joint Ventures and Mergers, Journal of Law and Economics, 28, p.311-333.

Papaconstantinou, G., 1990, Research Spillovers and Strategic Behavior, Paper submitted for the Fifth Congress of the European Economic Association 1990, Lisbon, Portual, 81p.

Peterson, J., 1991, Technology Policy in Europe: Explaining the Framework Programme and Eureka in Theory and Practice, Journal of Common Market Studies, 29, p.269-291.

Perez-Castrillo, D. and J. Sandonis, 1997, Disclosure of Know-how in Research Joint Ventures, International Journal of Industrial Organization, 15, p.51-76.

Poyago-Theotoky, J., 1995, Equilibrium and Optimal Size of Research Joint Venture in an Oligopoly with Spillovers, Journal of Industrial Economics, XLIII, 2, p.209226.

Scott, J.T., 1988, Diversification versus Cooperation in R\&D investment, Managerial and Decision Economics, 9, p.173-186.

Seade, J.K., 1980, The Stability of Cournot Revisited, Journal of Economic Theory, 23, p.15-27.

Shapiro, C. and R. Willig, 1990, On Antitrust Treatment of Production Joint Ventures, Journal of Economic Perspectives, 4, p.113-130.

Spence, M., 1984, Cost Reduction, Competition and Industry Performance, Econometrica, 52, p.101-121.

Veugelers, R. and K. Kesteloot, 1994, On the Design of Stable Joint Ventures, European Economic Review, 38, p.1799-1815.

Wolinsky, A., 1993, Regulation of Duopoly under Asymmetric Information, Mimeo, Northwestern University.

Yi, Sang-Seung, 1995, R\&D Cooperation, Product-Market Collusion and Welfare, Mimeo, Darthmouth College. 


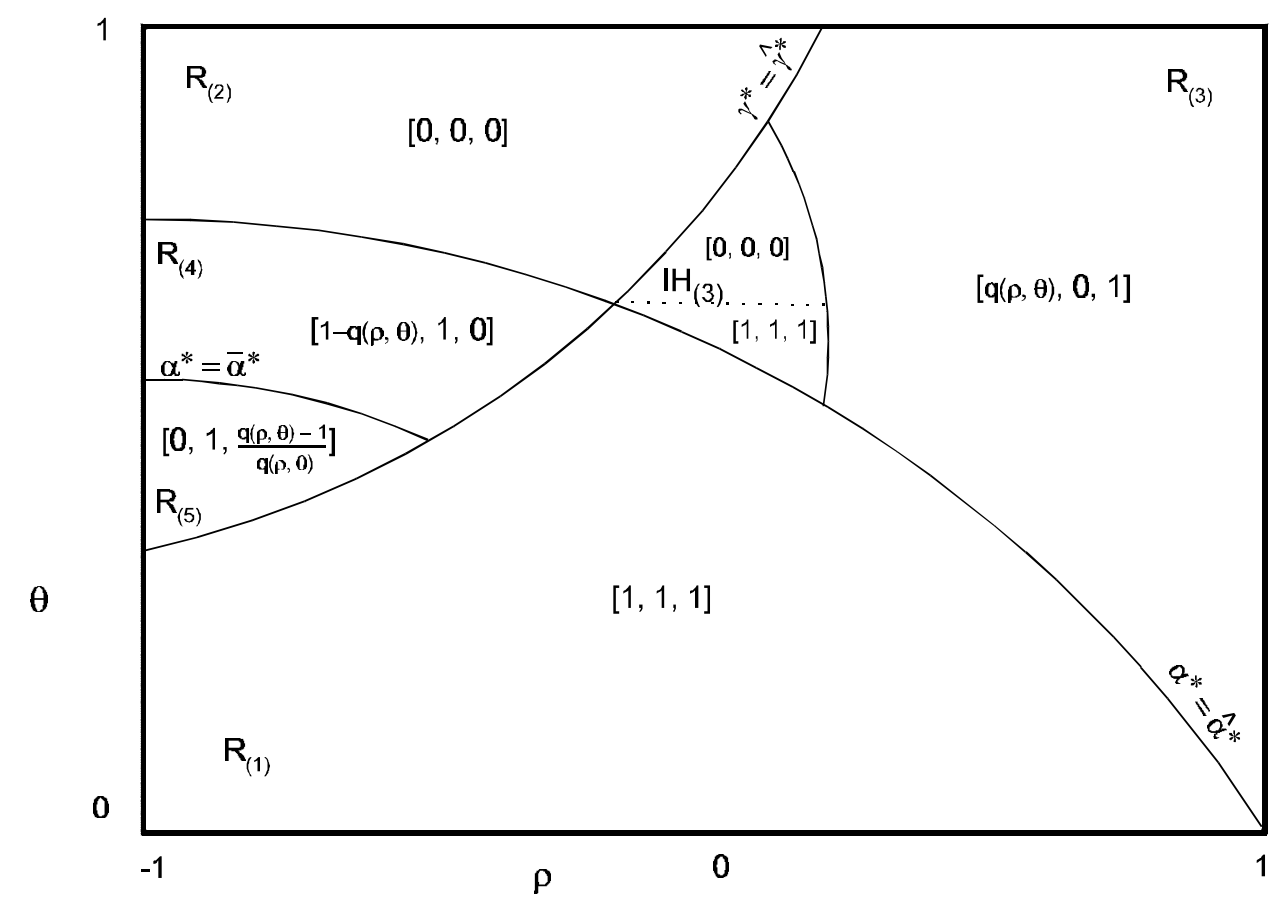

Figure 1: $\quad$ Second-Best Policy without Subsidies in Terms of Correlation of Types and Marginal Probability of Low Type 


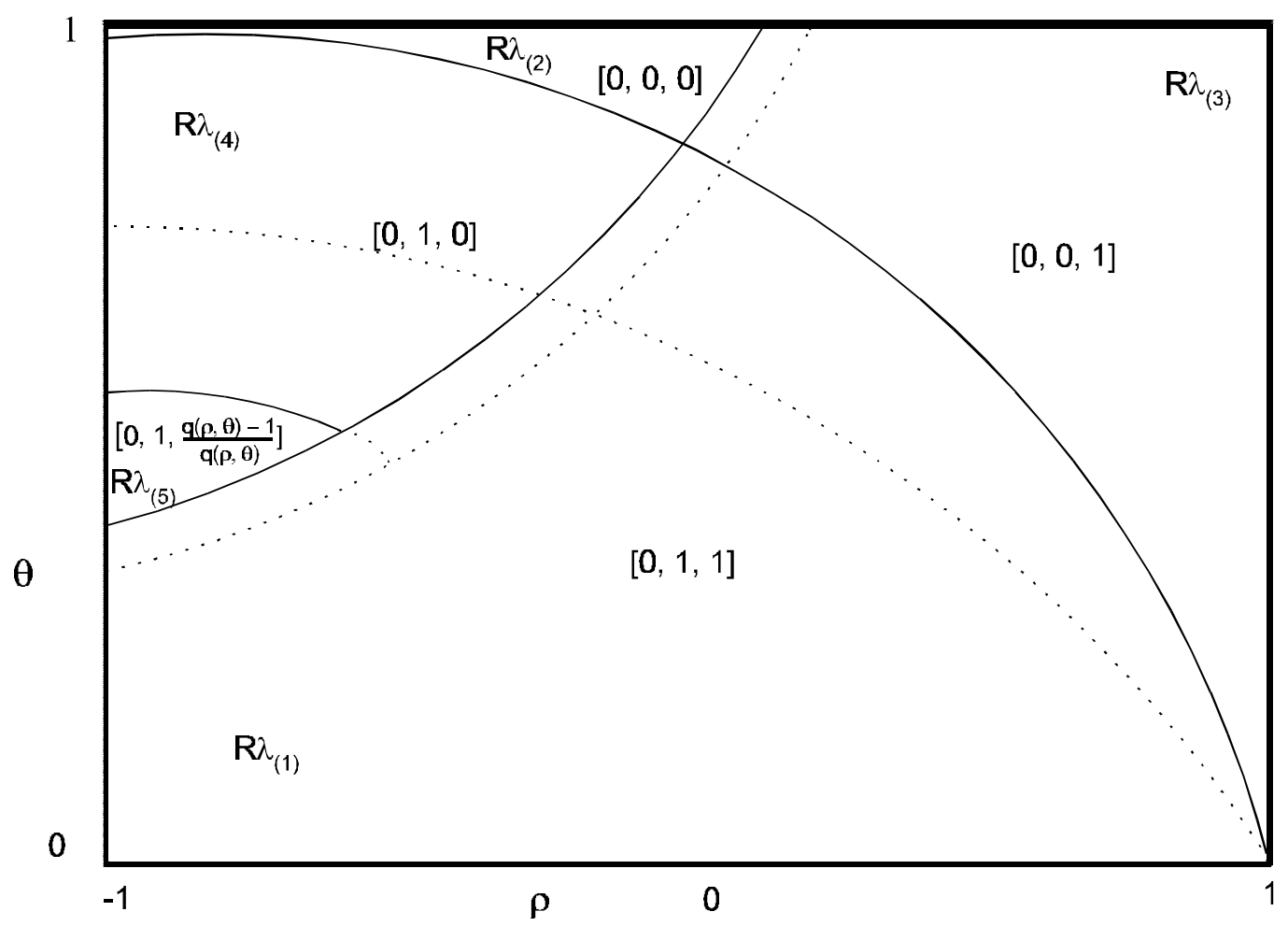

Figure 2: $\quad$ Second-Best R\&D Policy with Subsidies and Low Cost of Public Funds In Terms of Correlation of Types and Marginal Probability of Low Type 
